\title{
A review of small molecules and drug delivery applications using gold and iron nanoparticles
}

This article was published in the following Dove Medical Press journal:

International Journal of Nanomedicine

\author{
Hossein Jahangirian' \\ Katayoon Kalantari ${ }^{2}$ \\ Zahra Izadiyan ${ }^{3}$ \\ Roshanak \\ Rafiee-Moghaddam ' \\ Kamyar Shameli ${ }^{3}$ \\ Thomas J Webster' \\ 'Department of Chemical Engineering, \\ 3I 3 Snell Engineering Center, \\ Northeastern University, Boston, MA, \\ USA; ${ }^{2}$ Centre of Advanced Materials \\ (CAM), Faculty of Engineering, \\ University of Malaya, Kuala Lumpur, \\ Malaysia; ${ }^{3}$ Department of Environment \\ and Green Technology, Malaysia-Japan \\ International Institute of Technology, \\ Universiti Teknologi Malaysia, Kuala \\ Lumpur, Malaysia
}

Correspondence: Hossein Jahangirian Department of Chemical Engineering, 313 Snell Engineering Center, Northeastern University, 360 Huntington Ave, Boston, MA 02115, USA

Email kamran.jahangirian@gmail.com

\begin{abstract}
Conventional cancer treatment techniques show several limitations including low or no specificity and consequently a low efficacy in discriminating between cancer cells and healthy cells. Recent nanotechnology developments have introduced smart and novel therapeutic nanomaterials that take advantage of various targeting approaches. The use of nanotechnology in medicine and, more specifically, drug delivery is set to spread even more rapidly than it has over the past two decades. Currently, many nanoparticles (NPs) are under investigation for drug delivery including those for cancer therapy. Targeted nanomaterials bind selectively to cancer cells and greatly affect them with only a minor effect on healthy cells. Gold nanoparticles (AuNPs), specifically, have been identified as significant candidates for new cancer therapeutic modalities because of their biocompatibility, easy functionalization and fabrication, optical tunable characteristics, and chemophysical stability. In the last decade, there has been significant research on Au-NPs and their biomedical applications. Functionalized Au-NPs represent highly attractive and promising candidates for drug delivery, owing to their unique dimensions, tunable surface functionalities, and controllable drug release. Further, iron oxide NPs due to their "superparamagnetic" properties have been studied and have demonstrated successful employment in numerous applications. In targeted drug delivery systems, drug-loaded iron oxide NPs can accumulate at the tumor site with the aid of an external magnetic field. This can lead to incremental effectiveness in drug release to the tumor site and vanquish cancer cells without harming healthy cells. In order for the application of iron oxide NPs in the human body to be realized, they should be biodegradable and biocompatible to minimize toxicity. This review illustrates recent advances in the field drug and small molecule delivery such as fluorouracil, folic acid, doxorubicin, paclitaxel, and daunorubicin, specifically when using gold and iron oxide NPs as carriers of anticancer therapeutic agents.
\end{abstract}

Keywords: small molecules, drug delivery, nanoparticles, gold nanoparticles, iron oxide nanoparticles

\section{Introduction}

To date, small molecules are some of the most critical molecules for biological function, which most medicines contain. ${ }^{1}$ Many organic molecules show low solubility in aqueous media, and incomplete drug delivery as the main reason in $>40 \%$ of all drug failures. As high-throughput techniques continue to fabricate a number of chemical entities for treating complex disease pathways, there is an increased demand to find effective and significant molecular delivery methods in an appropriate manner. Therefore, there is a profound need to deliver a wide range of hydrophobic and neutral small molecules with exact spatiotemporal control. ${ }^{1}$

Cancer is the leading cause of death around the world. ${ }^{2}$ As a highly efficient technique for the treatment of cancer in the clinics, chemotherapy has been widely used. 
However, anticancer drugs with a small molecular structure have several limitations in direct administration such as adverse side effects, rapid elimination of drugs, nonspecific cytotoxicity, severe multidrug resistance, and low bioavailability. To solve the above mentioned limitations, several drug carriers at the nanoscale including metal nanoparticles (NPs), liposomes, ceramic materials, and polymeric micelles have been used. Systems with carrier-based delivery show significant therapeutic efficacy and lower side effects compared with free drugs. However, lower drug loading and unpredictable carrier metabolism or degradation in the body lead to very low therapeutic efficiency. ${ }^{3}$

A considerable amount of research has been conducted on drug delivery via polymeric scaffolds. Biomaterials used in drug delivery can be broadly categorized as 1) synthetic biodegradable polymers, which includes relatively hydrophobic materials such as the $\alpha$-hydroxy acids (such as polylactic-coglycolic acid [PLGA]), and polyanhydrides, and 2) naturally occurring polymers, such as complex sugars (hyaluronan, chitosan $[\mathrm{CHI}]$ ) and inorganics (hydroxyapatite). ${ }^{4}$ Despite the discovery of a large number of materials that could serve as therapeutics, very few candidates have shown clinical success. Poor activity in vivo is most often attributed to their low "bioavailability", the extent, and rate at which a drug reaches and affects the target tissue. However, the potential toxicity from dose dumping, inconsistent release, and drug-polymer interactions require detailed evaluation. ${ }^{5}$

Recently, the development of NPs for the anticancer agent delivery of small molecular structures has drawn great attention from the medical research community. In cancer treatment, small molecules used as routine usable agents of chemotherapeutics have some limiting characteristics in their clinical applications, such as low water solubility, nonspecific biodistribution, and lack of targeting as well as low therapeutic indices. Furthermore, drug-resistant development, shortly after initial treatment, reduces efficacy of not only conventional chemotherapeutics but also newer targeted therapeutic agents. However, the delivery of small molecules with therapeutic properties by NPs has some advantages that may overcome these limitations.

The US National Cancer Institute defined NPs as colloidal particles in the size range of $1-100 \mathrm{~nm}$. It is likely that NPs $>10 \mathrm{~nm}$ and $<100 \mathrm{~nm}$ are more effective. For the glomerular capillary wall, with the measurement of sieving coefficients, on the basis of sieving coefficients measured for the glomerular capillary wall, the estimated NP diameter as the threshold for first-pass elimination by the kidneys is $10 \mathrm{~nm} .{ }^{6}$ By contrast, the vasculature of a tumor is immature and leaking of macromolecules from the blood can take place in the interstitial space in tumor tissues. This phenomenon is called the "enhanced permeability and retention (EPR) effect". Based on evidence of accumulation, the effect of EPR is effective for both human cancers and animal tumor models. As mentioned, chemical molecules with a diameter in the range of $100 \mathrm{~nm}^{173}$ can leak from the blood and accumulate within the tissues of the tumor, but larger NPs show restricted diffusion into the extracellular space, which leads to limitations in the NP efficiency by preventing them from easily reaching cancer cells. Experimental results obtained from animal models suggest that particles with a size $<150$ $\mathrm{nm}$, neutral or slightly negative charged, have the ability to move through tumor tissues. NPs of the size range of 50-100 $\mathrm{nm}$ and a nearly neutral charge can penetrate throughout large tumors following systemic administration. Moreover, the addition of a targeting moiety to NPs can guide them to cells and tissues of tumors. ${ }^{7}$

This selective accumulation in cells and tissues of tumors gives the potential for NPs to significantly improve the therapeutic outcome of cancer treatment while minimizing the devastating side effects associated with many current therapies. NPs that carry a small molecule anticancer agent have several advantages such as solubility improvement, which facilitates drug delivery, greater half-life $\left(t^{1 / 2}\right)$ in circulation, enhanced accumulation of drugs to targeted cancer cells and tissues, stable and constant release of drugs, and reduced efflux pump-mediated drug resistance. One of the major challenges in the development and clinical application of NPs is understanding the precise mechanism of the release of anticancer agents from NPs and delivering them to the tissues of targeted tumors and cells. Moreover, the effects of NP biodistribution on the toxicity in major organs should be clarified. ${ }^{8}$

Several drugs conjugated to gold and iron NPs have been used for drug delivery systems (DDS), such as cisplatin, carboplatin, oxaliplatin, ${ }^{9}$ and epirubicine. ${ }^{10}$ In this review, we will focus primarily on 5-fluorouracil (5-FU), folic acid (FA), doxorubicin (DOX), paclitaxel (PTX), and daunorubicin (Dau) as drugs, which have been used for drug delivery using iron and gold NPs.

\section{Gold NP conjugates in DDSs}

DDSs provide positive attributes to a "free" drug by improvement in solubility, in vivo stability, and biodistribution. They can alter unfavorable pharmacokinetics of some "free" drugs as well. Furthermore, a large pharmaceutical loading for DDSs can create "drug reservoirs" for controlled and 
sustained release to maintain drug levels within a therapeutic window. ${ }^{11}$ Several materials can be used in formulations of NPs including polymers, lipids (liposomes), and viruses (viral-like NPs) with distinct characteristics. Organometallic and inorganic compounds as well as metals, like silica, gold, iron oxide (IO) NPs, and nanotubes, can be used as small molecule carriers. ${ }^{8,12-14}$ Some metal-based NPs potentially have the ability to mimic the function of an enzyme. Gold nanoparticles (Au-NPs) have displayed unique enzymatic properties that make them useful in biological and biomedical applications. Moreover, Au-NPs acting as artificial enzymes have shown "hidden talents", including their ability to mimic the functions of esterase, peroxidase, nuclease, superoxide dismutase, and catalase. Moreover, Au-NPs with either negative or positive surface charges reveal peroxidase mimicking activity. These enzyme-like activities of Au-NPs are related to functional groups and help researchers to design and develop biosensors, clinical studies, immunoassays, targeted drug delivery, bioimaging applications, and photothermal activity of microorganisms and cancer cells. ${ }^{3-7}$ Au-NPs can be made biocompatible, displaying no toxicity with facile synthesis, shape, and size tenability. In addition to biological safety and user-friendly techniques for constructing Au-NPs, they have no toxic degradation products. Metallic colloidal Au-NPs can be fabricated in various forms (dots, rods, etc) and are commercially available in different size ranges and are detectable at low concentrations. ${ }^{15}$ NPs can easily enter cells; however, the involved mechanism(s) are not well understood. It is thought that the NP influx occurs by endocytosis, where the particles are inserted and diffuse through the lipid bilayer of the cell membrane. Au-NPs even after protein linkage (like with antibodies) show an ability to enter cells without cytotoxic effects. ${ }^{16}$ They are conjugated with antibodies against exclusive cancer cell surface receptors that have been used to specifically bind to cancerous cells. Au-NPs with a size of $20 \mathrm{~nm}$ have been conjugated to different cellular targeting peptides to make functional NPs that penetrate biological membranes and target the nucleus. ${ }^{17}$

In the study of acute oral toxicity, no signs of gross toxicity or adverse effects were found when a Au-NP suspension with a size of $50 \mathrm{~nm}$ was investigated, the single dose for acute oral LD50 being $>5,000 \mathrm{mg} / \mathrm{kg}$ body weight. ${ }^{18}$ In addition, positive results from an in vivo mouse model were obtained with photothermal ablation therapy for colon carcinoma after intravenous administration of polyethylene glycol (PEG)-coated gold nanoshells. ${ }^{19}$ In 2016, Jiang et $\mathrm{al}^{20}$ developed a sensor of a fluorescence switch for facile and sensitive detection of both anticancer drug and calf thymus
DNA (ctDNA) based on glutathione (GSH)-stabilized gold nanoclusters (Au-NCs). The Au-NP fluorescence can be effectively quenched by mitoxantrone (MTX) due to the MTX absorption on the Au-NP surface and the transferring photoinduced electron process from Au-NCs to MTX subsequently. Their proposed method was used for ctDNA detection in real samples with significant results.

\section{5-FU release from Au-NPs}

$5-\mathrm{FU}$ is a pyrimidine analog that acts using the mechanism of irreversible inhibition of thymidylate synthase. It is used in different types of cancer treatment, such as in liver, colon, gastrointestinal, rectal, skin, ovarian, and breast cancers. 5-FU shows several side effects such as severe gastrointestinal toxicity, hematologic disturbance, skin reactions, severe bone marrow deficiency, hair thinning, hand-foot syndrome, and heart toxicosis, which lead to a limitation in its use. Moreover, it has low bioavailability with a short plasma half-life. $5-\mathrm{FU}$ is metabolized rapidly and should be administrated by intravenous injection. To overcome the mentioned problems, some approaches have been applied, such as the synthesis of 5-FU chemical derivatives and encapsulation of drugs into different delivery systems, such as ion exchange resins, polymeric particles, vesicular systems, and hydrogels. ${ }^{21}$ An overview of Au-NPs/5-FU and their applications is presented in Table 1.

Very few 5-FU/Au-NPs formulations have been tested against colorectal cancer cells. In one of the most recent studies, Safwat et al loaded 5-FU onto Au-NPs using two thiolcontaining ligands, thioglycolic acid (TGA) and GSH. They synthesized Au-NPs at different molar ratios of a 5-FU/ligand and evaluated them by different methods. A study of the anticancer efficacy of 5-FU/GSH-Au-NPs was done using flow cytometry in cancerous tissue obtained from patients having colorectal cancer. Au-NP stability and the profile of drug release were evaluated as a salt concentration function and $\mathrm{pH}$ of the solution. The 5-FU/ligand molar ratio of $1: 1$ for TGA-Au-NPs and 2:1 for GSH-Au-NPs was the optimum ratio of 5-FU loading. Coating Au-NPs with pluronic F127 led to improvement in stability against salinity. The release of 5-FU from the Au-NPs was $\mathrm{pH}$-dependent and where faster release was observed at $\mathrm{pH}<5$. 5-FU/GSH-Au-NPs, induced apoptosis and stopped the progression of cell cycle growth in colorectal cancer cells. Better anticancer effects against colon cancer cells was achieved for the 5-FU/GSH-Au-NPs compared with the free drug. ${ }^{21}$

For $>40$ years, 5-FU has been used as a chemotherapeutic agent against many types of cancer. As a pyrimidine 
Table I Overview of Au-NPs/5-FU and their applications

\begin{tabular}{|l|l|l|l|}
\hline Nanoparticles & Drugs & Applications & References \\
\hline Au-NPs/thioglycolic acid and glutathione & 5-FU & Patients having colorectal cancer & 21 \\
\hline Au-NPs/PEG & 5-FU & MI39 and M2I3 cells & 27 \\
\hline Porphyran-capped Au-NP-modified carbon paste electrode & 5-FU & Electrochemical sensor & 30 \\
\hline Au-NPs/polyamic acid & 5-FU & HeLa cells & 31 \\
\hline Fluorescent chitosan/silver-gold nanocomposite & 5-FU & Colorimetric sensing and 5-FU delivery & 32 \\
\hline Au-NPs/chitosan & 5-FU & HepG2 & 33 \\
\hline Au-NPs capped with cetyltrimethylammonium & 5-FU & HaCaT & 34 \\
\hline
\end{tabular}

Abbreviations: Au-NPs, gold nanoparticles; 5-FU, 5-fluorouracil; PEG, polyethylene glycol.

antagonist, 5-FU acts as a block for the synthesis of RNA or DNA nucleotides. High doses of 5-FU must be used to attain the required therapeutic level. However, one of the main restrictions to its use is the development of multidrug resistance in the tumor cells. Moreover, continuous administration of high doses of 5-FU causes severe toxic effects on the surrounding living cells. ${ }^{22,23}$ Solid lipid nanoparticles (SLNs) are colloidal particles consisting of lipid materials, which are stabilized with the use of varying types of surfactants. SLNs are received readily by the skin due to their hydrophobic nature, enabling the encapsulation of the hydrophobic drugs with ease. ${ }^{24}$ Khallaf et al applied SLN to Ehrlich's ascites tumors in order to evaluate the ability of SLN to deliver chemotherapeutic agents via the skin. The Ehrlich tumor is a spontaneous murine mammary adenocarcinoma. They engineered highly penetrating, shell-enriched NPs, which were loaded with a hydrophilic chemotherapeutic agent, 5-FU. Various ratios of lecithin and poloxamer 188 have been used by them for the production of shell-enriched NPs by enabling reversed micelles within this region of the shell-enriched SLN. The 5-FU localization within the shell region of the SLN was confirmed using 5-FU Au-NPs as a tracer. The colloidal Au-NPs were localized in the shell region, forming a papillated zone at the surface of the SLN. SLNs were introduced within the hydrogel shape of sodium carboxyl methylcellulose and then used for the mice skin bearing Ehrlich ascites carcinoma. For 6 months, the treatment of mice was accomplished with the gel twice daily. SLN-treated mice exhibited reduced inflammatory reactions, with reduced degrees of keratosis. ${ }^{25}$

Studies demonstrated that FA, or vitamin B9, played a vital role in mammalian cell growth. FA has a high binding affinity with the folic acid receptor (FAR), which is upregulated on the surface of many cancer cells, and limited distribution was found in normal tissues. ${ }^{26}$ Several studies have reported NPs with FA for site-specific targeting and an improvement of FAR-mediated uptake by cancer cells. In recent research, Ngernyuang et al developed a new method for drug sensitivity for carrying drugs through the conjugation of Au-NPs by FA as a targeting agent. 5-FU and FA were used to functionalize the Au-NPs, using a shell of PEG as a linker. They tested the cytotoxicity of Au-NPs-PEG-5-FUFA in CCA cell lines (M139 and M213), which express FAR. The obtained results revealed that Au-NPs-PEG-5-FU-FA increased the cytotoxic effects in M213 and M139 cells by $7.95 \%$ and $4.76 \%$, respectively, compared with those treated with free 5-FU + FA. As shown in Figure 1, it was found that the Au-NPs-PEG-5-FU-FA cytotoxicity correlated with the expression of FAR, suggesting the potential for using FA as a targeted therapy. The cytotoxicity mechanism was mediated via the mitochondrial apoptotic pathway as determined by an apoptosis array. Their results shed some light on the use of $\mathrm{Au}-\mathrm{NPs}$ for the conjugation of potential compounds and FA as a targeted therapy, which contribute to the improvement of the efficacy of anticancer drugs. ${ }^{27}$

Porphyran (PFR) is a well-known sulfated polysaccharide that is extracted from red seaweed. The application of PFR for the green synthesis of metal NPs has gained prominence as a result of its biocompatibility, biodegradability, nontoxicity, low cost, and natural abundance. Moreover, PFR can act simultaneously as a reducing and capping agent, which eliminates the need to add other reagents during the synthetic process. Therefore, PFR can be considered as a convenient green material for NP production, and the nanocomposite based on these two materials may find a promising and attractive applicability in the chemical modification of electrodes. ${ }^{28,29}$ Carbon paste electrodes modified with porphyrancapped Au-NPs (CPE/Au-NPs-PFR) were used by Lima et al to detect 5-FU as an anticancer drug. ${ }^{30}$ They synthesized Au-NPs by using PFR that acts as a stabilizing and reducing agent. At $70^{\circ} \mathrm{C}, 128.7 \mathrm{~nm}$ was the smallest particle size that was obtained. By using cyclic voltammetry (CV) and 

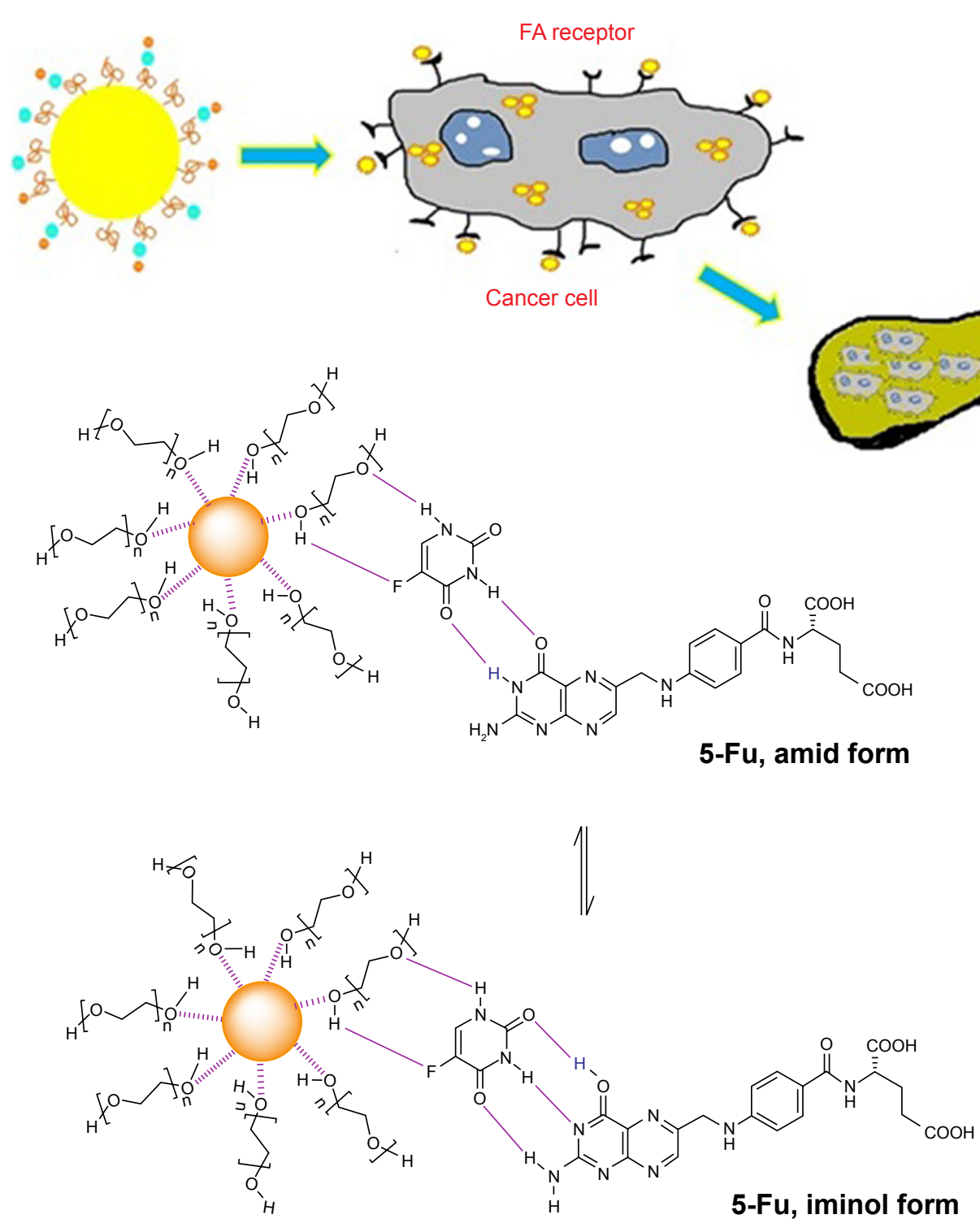

Figure I Targeted delivery of 5-FU to cholangiocarcinoma cells using folic acid.

Note: Data from Ngernyuang et al..$^{27}$

Abbreviation: 5-FU, 5-fluorouracil.

electrochemical impedance spectroscopy experiments, the electrochemical performance of the electrodes was enhanced by using the nanocomposite as a consequence of the high conductivity and large surface area presented by the Au-NPs. The CPE/Au-NPs-PFR was able to electrocatalyze the 5-FU oxidation by $\mathrm{CV}$ and differential pulse voltammetry. Besides the good sensitivity, CPE/Au-NPs-PFR revealed optimal reproducibility and did not suffer a significant interference from potentially electroactive biological compounds. The good analytical performance of the modified electrode for the determination of 5-FU in pharmaceutical formulations was confirmed with significant percent recoveries and good relative $\mathrm{SD}$.

\section{FA release from Au-NPs}

The surfaces of Au-NPs have a strong binding affinity toward amines, thiols, and disulfides. ${ }^{7}$ Particularly, the simple Authiol chemistry affords surface conjugation with different types of proteins, peptides, and DNA, either via a naturally available thiol group such as cysteine or others with an incorporated thiol group. Hence, for NP internalization, the surface can be modified using a ligand known to be efficiently internalized by target cells via receptor-mediated endocytosis.

Au-NPs with a functionalized surface with a specific antibody, such as the anti-EGFR for epithelial cancer cells, have been developed for diagnostic applications and thermophototherapy of cancer cells. ${ }^{11-14}$ Furthermore, several other 
agents including antibodies, aptamers, peptides, and proteins have also been recognized for targeting cancer cells. For tumor-specific delivery, the FAR is known as a useful target compared with the above different strategies for NP receptor-mediated endocytosis, because FARs are upregulated on a variety of human cancer cells including breast cancers, endometrium, ovaries, kidneys, brain, colon, and myeloid cells of hematopoietic origin. The folate receptors lacking in nonproliferating normal cells differentiate them from tumor cells. ${ }^{24} \mathrm{FA}$ has a high affinity for cell surface receptors. In addition, it is nonimmunogenic, highly stable, and cheap with a small molecular size. Thus, it facilitates the easy internalization of NPs through the cell membrane. The applications of Au-NPs/FA are summarized in Table 2.

Currently, the development of the Au-NP-folate conjugate system of high efficiency is a challenge in this field. Numerous research studies using PEG, poly(amidoamine) dendrimers, PLGA, poly-L-lysine (PLL), and poly(D,Llactic-co-glycolic acid) and their block copolymers have been reported to be in development to design a biodegradable hydrophilic folate-NP conjugate for cancer targeting systems. ${ }^{26-30}$ These targeting systems show good efficiency in their internalization and biocompatibility; however, the large size of these macromolecule-based systems does not

Table 2 Overview of Au-NPs/FA and their applications

\begin{tabular}{|c|c|c|c|}
\hline NPs & $\begin{array}{l}\text { Drugs/targeting } \\
\text { agent }\end{array}$ & Applications & References \\
\hline Glutathione-capped Au-NPs & FA & $\begin{array}{l}\text { HeLa and mouse } \\
\text { fibroblast (FB) cells }\end{array}$ & 35 \\
\hline Polyethylenimine-entrapped Au-NPs & FA & $\begin{array}{l}\text { KB-HFAR cells and } \\
\text { KB-LFAR cells }\end{array}$ & 37 \\
\hline $\begin{array}{l}\text { Negatively charged Au-NPs with the transferrin targeting ligands and positively } \\
\text { charged Au-NPs with the folate receptor targeting ligands }\end{array}$ & FA & $\begin{array}{l}\text { Prostate cancer } \\
\text { cells }\end{array}$ & 41 \\
\hline $\begin{array}{l}\text { Au-NPs prepared by using a strong antioxidant quercetin and dextran sulfate } \\
\text { as a stabilizing agent }\end{array}$ & FA & $\begin{array}{l}\text { NIH 3T3 FB and } \\
\text { human breast } \\
\text { cancer cell lines } \\
\text { (MCF-7) }\end{array}$ & 42 \\
\hline Au-NPs functionalized with FA & FA & Cervix cancer cells & 43 \\
\hline Positively charged Au-NPs capped with folate quaternary chitosan & FA & $\begin{array}{l}\text { Human umbilical } \\
\text { vein endothelial cells }\end{array}$ & 44 \\
\hline Gum kondagogu-capped Au-NPs & FA & $\begin{array}{l}\text { A549 (lung cancer) } \\
\text { cells }\end{array}$ & 38 \\
\hline Folate-conjugated Au-NPs & FA & $\begin{array}{l}\text { KB cancer cells and } \\
\text { L929 normal cells }\end{array}$ & 45 \\
\hline Folate-conjugated gold-photoactive polymer NPs & FA & $\begin{array}{l}\text { C6 glioma brain } \\
\text { cancer cells }\end{array}$ & 46 \\
\hline $\begin{array}{l}\text { Au-NPs on FA-modified dendritic mesoporous silica-coated reduced graphene } \\
\text { oxide nanosheets }\end{array}$ & FA & $\begin{array}{l}\text { MCF-7 (human } \\
\text { breast carcinoma } \\
\text { cell lines) and A549 } \\
\text { (human lung } \\
\text { carcinoma cell lines) }\end{array}$ & 39 \\
\hline $\begin{array}{l}\text { Au-NPs/dimethyldioctadecylammonium/bromide/ } \\
\text { dioleoylphosphatidylethanolamine }\end{array}$ & FA & MCF-7 and A549 & 47 \\
\hline Modified Au-NPs with covalently bonded thiol linkers & FA & MDA-MB-23I & 48 \\
\hline $\begin{array}{l}\text { Gold nanorods/amphiphilic polysaccharide-based graft copolymer and an amino } \\
\text { derivative of the } \alpha, \beta \text {-poly( } N \text {-2-hydroxyethyl)-D,L-aspartamide }\end{array}$ & FA & I6HBE and $\mathrm{HDFa}$ & 49 \\
\hline Gold nanobipyramids & FA & MCF-7 & 40 \\
\hline Biocapped Au-NPs using hirsutus leaf extract & $\mathrm{FA}$ & $\begin{array}{l}\text { HeLa, RKO, and } \\
\text { A549 }\end{array}$ & 50 \\
\hline FA-Au@poly(acrylic acid)/mesoporous calcium phosphate Janus NPs & FA & HeLa & 51 \\
\hline Au-NPs modified with thionine & FA & A549 & 52 \\
\hline Poly(ethylene glycol)-coated gold@iron oxide core-shell NPs & FA & $\mathrm{KB}$ and MCF-7 & 53 \\
\hline
\end{tabular}

Abbreviations: Au-NPs, gold nanoparticles; FA, folic acid; HBE, human bronchial epithelial cells; HDFa, human dermal fibroblasts; MDA-MB, typical human breast cancer cells; RKO, human colon carcinoma cell line; HeLa, cell line derived from cervical cancer cells; HFAR, high folate receptor; LFAR, low folate receptor; HFAR, high folic acid receptor; LFAR, low folic acid receptor; NPs, nanoparticles. 
facilitate intravenous delivery. ${ }^{31}$ In order to effectively pass a NPs-folate-conjugated system from the blood stream and reach the target cell of interest, their size and colloidal stability in the physiological environment should be considered as important factors. ${ }^{35}$ The closest chemical formula of FA is $\mathrm{C}_{19} \mathrm{H}_{19} \mathrm{~N}_{7} \mathrm{O}_{6}(\mathrm{Mw}=441.4 \mathrm{Da}$ ). Folate (the salt of FA) is an ingredient needed for the biosynthesis of purines and pyrimidines in the pathway of DNA synthesis. ${ }^{36}$

Zhang et $\mathrm{al}^{35}$ developed a simple chemical technique to couple FA on the Au-NPs surface using GSH. GSH is a natural tripeptide ( $\gamma$-Glu-Cys-Gly) with small size that has two carboxyl groups, one -SH group and one amino group. Moreover, it is the most abundant thiol species in the cytoplasm and a major reducing agent in biochemical processes. It has been used as a coupling and stabilizer agent in the fabrication of GSH-capped Au-NPs (GSH-Au-NPs). Through the thiol group of the cysteine moiety, GSH was immobilized on the surface of Au-NPs, and FA was conjugated with Au-NPs via the reaction between carboxyl groups of GSH and amino groups of FA. For the preparation of fluorescently labeled NPs coupled with fluorescein isothiocyanate (FITC), GSH also provided an amino group. By using confocal laser scanning microscopy and transmission electron microscopy, they confirmed the targeting of FA-GSH-Au-NPs to HeLa cells with a high-level folate receptor expression and $10^{2}$ cell $/ \mathrm{mL}$ as a detection limit. ${ }^{32}$

In 2016, Zhou et al presented a facile technique for the preparation of FA-targeted multifunctional Au-NPs using polyethylenimine (PEI) modified with PEG as a template for tumor computed tomography imaging applications. In their study, PEG monomethyl ether and FA-linked PEG have been used for the modification of PEI; a fluorescein isothiocyanate was applied as a template for the fabrication of the Au-NPs, followed by transformation of the remaining PEI surface amines to acetamides. The obtained FA-conjugated, PEI-entrapped Au-NPs (FA-Au PENPs) have a gold core size of $2.1 \mathrm{~nm}$ with water solubility, colloidal stability, and noncytotoxicity at a Au concentration range of $100-800 \mu \mathrm{M}$. Flow cytometry and confocal microscopy data showed that the FA-Au PENPs were able to target cancer cells. ${ }^{37}$

Recently, Kumar et al developed a green synthesis technique for gum kondagogu-capped Au-NPs (GK-Au-NPs) by a natural polysaccharide. The anionic gum-capped GKAu-NPs enabled the coupling of FA and FITC to fabricate a fluorescently labeled Au-NP (F2-Au-NP) successfully. Activity of F2-Au-NPs was investigated on both cancer cells: folate receptor positive (MCF-7) and folate receptor negative (A549). Characterization of the physicochemical properties showed that NPs have a size of $37 \mathrm{~nm}$, smooth surface, Au-NPs crystallinity, and existence of gum kondagogu in the F2-Au-NPs. Cellular uptake of F2-Au-NPs revealed an excellent affinity toward folate receptor-positive cells. An in vitro viability study showed biocompatibility in high levels for GK-Au-NPs and F2-Au-NPs in A549 and MCF-7 cells. ${ }^{38}$

Malekmohammadi et al prepared a new sandwich-like nanocomposite as a multifunctional smart nanocarrier for targeting curcumin (Cur) delivery and cell imaging by immobilizing Au-NPs on FA-modified, dendritic, mesoporous, silica-coated, reduced graphene oxide nanosheets (Au-NPs@GFMS). The nanocarrier exhibited a number of interesting properties, including good biocompatibility, biodegradability, and suitable surface area, which resulted in high drug loading capacity. In addition, this new DDS showed sustained-release and $\mathrm{pH}$-responsive properties. The in vitro cytotoxicity test of the free curcumin, free nanocarrier (Au-NPs@GFMS), curcumin-loaded, folateconjugated nanocarriers (Cur-Au-NPs@GFMS), and curcumin-loaded nanocarriers without folate conjugation (Cur-Au-NPs@GAMS) against two human cancer cell lines, specifically MCF-7 (human breast carcinoma cell lines) and A549 (human lung carcinoma cell lines), demonstrated that the therapeutic efficacy of Cur-Au-NPs@ GFMS was significantly greater than those of other compounds. This is because the cancerous cells can uptake the folate-conjugated drug nanocarrier via a receptor-mediated mechanism. Fluorescence microscopic images and different staining techniques were also used to visualize the cellular uptake, anticancer activity, specific targeting ability, and photothermal potency of Cur-Au-NPs@GFMS toward the MCF-7 cancer cells. ${ }^{39}$

Figure 2 presents the synthesis of bioconjugated gold nanobipyramids (Au-NBPs) for the detection of surfaceenhanced raman scattering (SERS) and near-infrared (NIR)triggered photothermal therapy (PTT) in breast cancer. Generally, Au-NBPs were first encoded with the Raman reporter 2-naphthalenethiol (2-NAP) via the $\mathrm{Au}-\mathrm{S}$ bond. To specify enhancement for the recognition of MCF-7 cancer cells, NAP-Au NBPs were functionalized with heterofunctional thiol-PEGamine (SH-PEG-NH ${ }_{2}$ ), and subsequently FA was covalently grafted to the PEG-NAP-Au NBPs through the carboxyl group of the FA reaction and a free amine group of SH-PEG-NH ${ }_{2}$. In the final step, the obtained bioconjugated $\mathrm{Au}-\mathrm{NBPs}$ were applicable for the detection of SERS and NIR-triggered PTT in breast cancers.

\section{DOX delivery by Au-NPs}

As shown in Table 3, DOX is one of the most used chemotherapeutic agents. Although it shows a killing ability of the cancerous cells by inhibition of the nucleic acid synthesis 


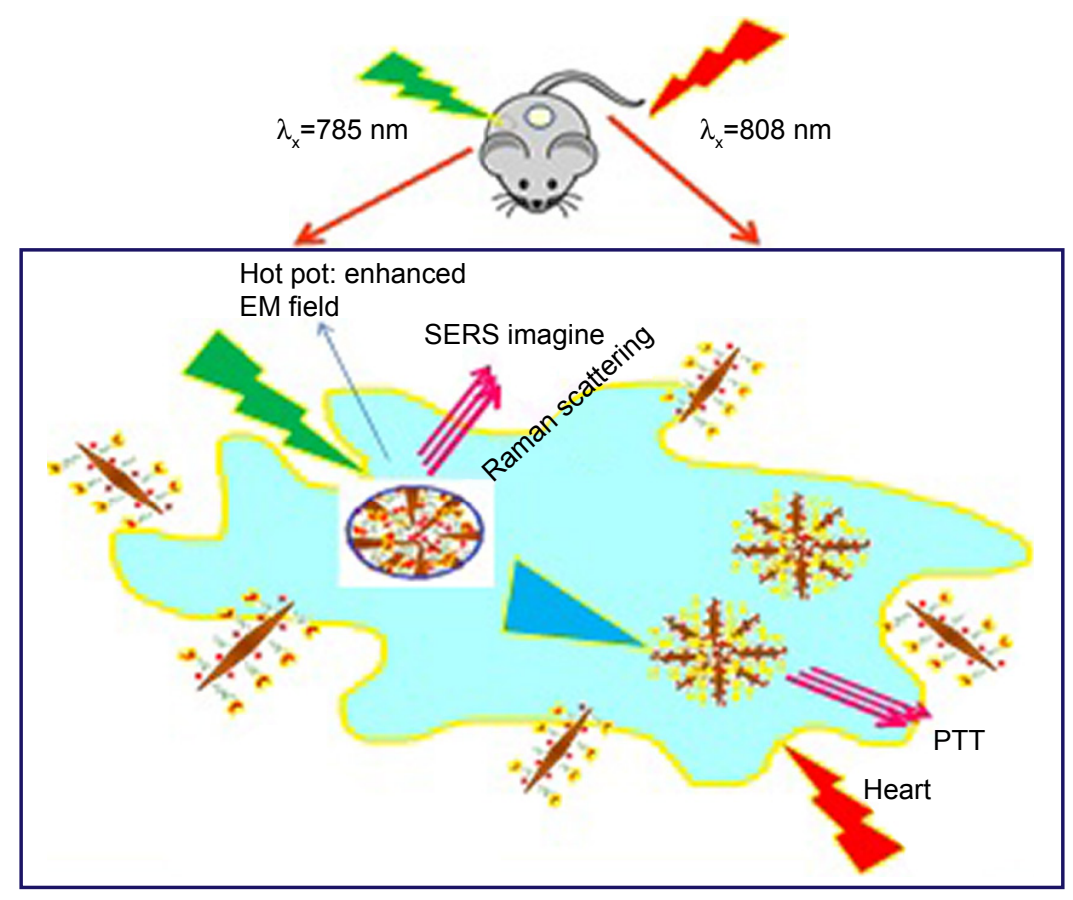

Figure 2 Bioconjugation of gold nanobipyramids for the detection of SERS and targeted photothermal therapy in breast cancer.

Note: Data from Feng et al. ${ }^{40}$

Abbreviations: SERS, surface-enhanced raman scattering; PTT, photothermal therapy; EM, electromagnetic field.

within cells, there are three main problems that should be solved with DOX: 1) it has a short lifetime in the human body, 2) it shows a large volume of distribution and high toxicity, and 3) it has a narrow therapeutic index due to low solubility. To overcome the DOX nonspecificity and high toxicity, many studies have been done and proposed on DOX conjugation to hydrophilic polymers leading to reduced toxicity levels while sustaining therapeutic efficacy. ${ }^{54}$ Specifically, polymer NPs are emerging as a useful tool for a wide variety of therapeutic and biomedical applications, including DOX delivery.

Manivasagan et al proposed multifunctional, DOX-loaded, fucoidan-capped Au-NPs (DOX-Fu Au-NPs) for drug delivery and photoacoustic imaging (PAI). Biocompatible Au-NPs were fabricated through a naturally occurring fucoidan $(\mathrm{Fu})$ as a reducing and capping agent. At $\mathrm{pH} 4.5$, the DOX release from DOX-Fu Au-NPs was greater than at $\mathrm{pH}$ 7.4. The in vitro cytotoxic effect of DOX-Fu Au-NPs, DOX, Fu Au-NPs, and fucoidan showed reduced proliferation of human breast cancer cells at an inhibitory concentration of 5, 15, 30, and $35 \mu \mathrm{g} / \mathrm{mL}$, respectively, at 24 hours. In a concentration-dependent manner, DOX-Fu Au-NPs induced both early and late apoptosis compared with untreated control cells. The ability of DOX-Fu $\mathrm{Au}-\mathrm{NPs}$ as a contrast agent (CA) for in vitro breast cancer imaging with PAI was also demonstrated successfully. ${ }^{54}$

In 2018, Ramalingam et al developed a DOX-conjugated DDS on the Au-NPs surface of polyvinylpyrrolidone (PVP).
Their results showed that the viability of cancer cells from human lungs can be reduced significantly by the combination of highly effective cellular entry and a responsive intracellular release of DOX from the DOX@PVP-Au-NPs complex. They demonstrated that the in vitro cytotoxic effect of PVPAu-NPs, free DOX, and DOX@PVP-Au-NPs inhibited the proliferation of human lung cancer cells at an appropriate IC50 concentration, and also they increased the generation of ROS, sensitized mitochondrial membrane potential, and induced both early and late apoptosis in lung cancer cells. In addition, DOX@PVP-Au-NPs highly upregulated tumor suppressor gene expression compared with DOX and PVPAu-NPs and induced intrinsic apoptosis in lung cancer cells. ${ }^{55}$

DOX shows a cumulative dose-dependent side effect of cardiotoxicity. Du et al designed an Au-NP-based DDS to solve this problem. They synthesized five thiolated DOX analogs and evaluated their biological activities. Then, two of the fabricated analogs and PEG-stabilizing ligands were conjugated to Au-NPs and the Au-DOX constructs were investigated. The obtained results revealed that native drug release was achievable by the action of reducing agents such as under acidic or GSH conditions, but reductive drug release was the cleanest release profile. Au-NPs (Au-DOX) were fabricated with various loading values of PEG and DOX, and one formulation was investigated for toxicity and stability of mammalian cells. The results indicated that the construct was stable under physiological conditions. 
Table 3 Overview of Au-NPs/DOX, Au-NPs/paclitaxel (PTX), and their applications

\begin{tabular}{|c|c|c|c|}
\hline NPs & $\begin{array}{l}\text { Drugs/targeting } \\
\text { agent }\end{array}$ & Applications & References \\
\hline Au-NPs pectin (Pec-Au-NPs) & DOX & Breast cancer cells & 57 \\
\hline DOX-loaded fucoidan-capped Au-NPs & DOX & Human breast cancer cells & 54 \\
\hline Protein-gold cluster-capped mesoporous silica NPs & DOX/gemcitabine & A549 lung cancer cells & 58 \\
\hline $\begin{array}{l}\text { Gelatin-DOX conjugate (GLT-DOX)-coated Au-NPs } \\
\text { (DOX-GLT/EGCG Au-NPs) }\end{array}$ & DOX & PC-3 cancer cell & 59 \\
\hline Biosynthesized Au-NP Peltophorum pterocarpum & DOX & $\begin{array}{l}\text { Cancer cells (A549, BI6FI0) } \\
\text { and tumor growth in an } \\
\text { in vivo model }\end{array}$ & 60 \\
\hline Gelatin-coated Au-NPs & DOX & MCF-7 breast cancer cells & 61 \\
\hline Au-NPs/polyvinylpyrrolidone & DOX & $\begin{array}{l}\text { A549, } \mathrm{H} 460 \text {, and } \mathrm{H} 520 \\
\text { lung cancer cells }\end{array}$ & 55 \\
\hline DOX-loaded Au-NPs & DOX & $\begin{array}{l}\text { A2780 human ovarian cancer } \\
\text { cell line }\end{array}$ & 56 \\
\hline Pectin-capped Au-NPs & DOX & $\begin{array}{l}\text { Human Caucasian } \\
\text { hepatocyte cells }\end{array}$ & 62 \\
\hline $\begin{array}{l}\text { Human serum albumin (HSA)-coated gold nanorods } \\
\text { (GNR/PSS/HSA NPs) }\end{array}$ & DOX & $\begin{array}{l}\text { Combined cancer } \\
\text { photothermal therapy } \\
\text { and chemotherapy }\end{array}$ & 63 \\
\hline Gold nanoplatform targeting carbonic anhydrase IX epitope & DOX & HT29 tumor cells & 64 \\
\hline Oligonucleotide-conjugated Au-NP & DOX & SW480 cells & 65 \\
\hline Oligonucleotides attached to Au-NP & DOX & SW480 & 65 \\
\hline Colloidal Au-NPs & DOX & HepG2 & 66 \\
\hline $\mathrm{Au} / \mathrm{Fe}_{3} \mathrm{O}_{4}$ & DOX & Targeted chemo-photothermal & 67 \\
\hline $\begin{array}{l}\text { Cisplatin and DOX-bioconjugated bromelain-encapsulated } \\
\text { Au-NPs }\end{array}$ & DOX & MG-63 and Saos-2 & 68 \\
\hline Platinum (core)-gold (shell) bimetallic NPs with chitosan & DOX & $\begin{array}{l}\text { HEK293, Caco-2, HepG2, } \\
\text { and MCF-7 }\end{array}$ & 69 \\
\hline Magnetic and Au-NP-embedded silica nanoshuttles & DOX & HeLa & 70 \\
\hline $\begin{array}{l}\text { Ultrasmall Au-NPs were appended to the openings of mesoporous } \\
\text { silica NPs }\end{array}$ & DOX & A549 & 71 \\
\hline Multifunctional Au-NP & DOX & A549 & 72 \\
\hline Fetuin-conjugated Au-NPs & DOX & $\mathrm{NCl}-\mathrm{H} 460$ & 73 \\
\hline Au-NPs coated & DOX & VX2 and raw 264.7 & 74 \\
\hline Asialoglycoprotein receptor/PTX-conjugated Au-NPs & PTX & Liver tumor (HepG2) cells & 75 \\
\hline Gold NP-coated pluronic-b-poly(L-lysine) NPs & PTX & MDA-MB-23I cells & 76 \\
\hline $\begin{array}{l}\text { Au-NPs with two-layer (hexadecanethiol/phosphatidylcholine) } \\
\text { and three-layer (with high-density lipoprotein) NPs }\end{array}$ & PTX & Lung cancer & 77 \\
\hline Biocompatible Au-NPs/chitosan oligosaccharide & PTX & MDA-MB-23I & 78 \\
\hline Gold-PTX nanoconjugate & PTX & H460 and H460PTX & 79 \\
\hline $\begin{array}{l}\text { Dithiocarbamate-functionalized PAMAM dendrimer used to cross- } \\
\text { link the shell of arginine Au-NPs }\end{array}$ & PTX & BI6FIO cells & 80 \\
\hline Polymer-coated gold/graphene hybrid & PTX & MCF-7 and $16 \mathrm{HBE}$ & 81 \\
\hline $\begin{array}{l}\text { Liposomes and Au-NPs used to construct a liposome with a hybrid } \\
\text { cluster bomb structure }\end{array}$ & PTX & HepG2 & 82 \\
\hline $\begin{array}{l}\text { Multifunctional nanoparticulate theranostic system simultaneously } \\
\text { encapsulating PTX, Au-NPs, and iron oxide NPs in poly(ethylene } \\
\text { oxide)-block-poly(E-caprolactone) }\end{array}$ & PTX & MCF-7 and MDA-MB-23I & 83 \\
\hline
\end{tabular}

Abbreviations: Au-NPs, gold nanoparticles; DOX, doxorubicin; NPs, nanoparticles; PAMAM, poly(amidoamine); PTX, paclitaxel; HSA, human serum albumin; PSS, poly(sodium 4-styrenesulfonate). 
No histopathology was conducted in Au-DOX-treated mice and no differences were observed from mice treated with saline, while mice treated with a DOX equivalent dose showed significant observable lesions. ${ }^{56}$

As depicted in Figure 3, negatively charged Au-NCs@ BSA were attached to a mesoporous silica nanoparticle (MSN)-NH ${ }^{3+}$ surface with positively charged simple mixing in a solution with neutral aqueous solutions saturated in cargo molecules. Hence, guest molecules were trapped both within the porous channels of MSN and in the capping layer of Au-NC@BSA. Figure 3 showed the successful design of the MSN-Au-NC@BSA as a nanocarrier. The DOX and BSA protein interaction was found to induce the formation of a highly loaded shell around gemcitabine-loaded MSN NPs leading to exceptionally high payloads. An overview of Au-NPs/DOX and their applications is shown in Table 3.

\section{Delivery of PTX using Au-NPs}

PTX, an isolated product from the Pacific yew bark, ${ }^{43}$ is one of the chemotherapeutic drugs with a significant effect. Promotion and stabilization of microtubes and further G2 or $\mathrm{M}$ phases of the cell cycle inhibition followed by the death of cells are its mechanism in the treatment of several cancer types. However, PTX has been categorized as a class IV chemical drug according to the Biopharmaceutical Classification System, because it has low permeability and water solubility. ${ }^{84}$
Gao et al fabricated asialoglycoprotein receptor (ASGP-R)-targeting, and PTX-conjugated Au-NPs (galactose/PTX-Au-NPs) for the precise treatment of liver cancer (HepG2) cells. Based on their findings, for the designed conjugate, the tumor cell selectivity was close to six times of that incubated with control conjugates without Gal modification in liver normal (L02) cells. The drug level in the tumor vs the liver of Gal/PTX-Au-NPs was $121.0 \%$ at 8 hours postinjection, a fold increase of 15.7 in tumor specificity compared with that of Au-NPs conjugated with PTX. ${ }^{75}$

Sun et al used an easy one-step technique to synthesize Au-NP-coated pluronic-b-poly(L-lysine) NPs (pluronicPLL@Au-NPs). Then they employed it as a delivery carrier for PTX in chemo-photothermal therapy, with pluronicPLL as the reducing agent for Au-NPs synthesis. MTT and calcein-AM assays were applied to determine cell viability of MDA-MB-231 cells treated with PTX-loaded pluronicPLL@Au-NPs, and cells were then irradiated with near infrared light. In vitro cytotoxicity and blood compatibility results showed excellent biocompatibility of the pluronicPLL@Au-NPs. MDA-MB-231 cells treated with PTXloaded pluronic-PLL@Au-NPs showed higher cytotoxicity compared with Taxol alone. As confirmed by in vitro and in vivo studies, the as-prepared pluronic-PLL@Au-NPs are excellent products for chemo-photothermal therapy. ${ }^{76}$ An overview of Au-NPs/PTX and their applications is shown in Table 3.

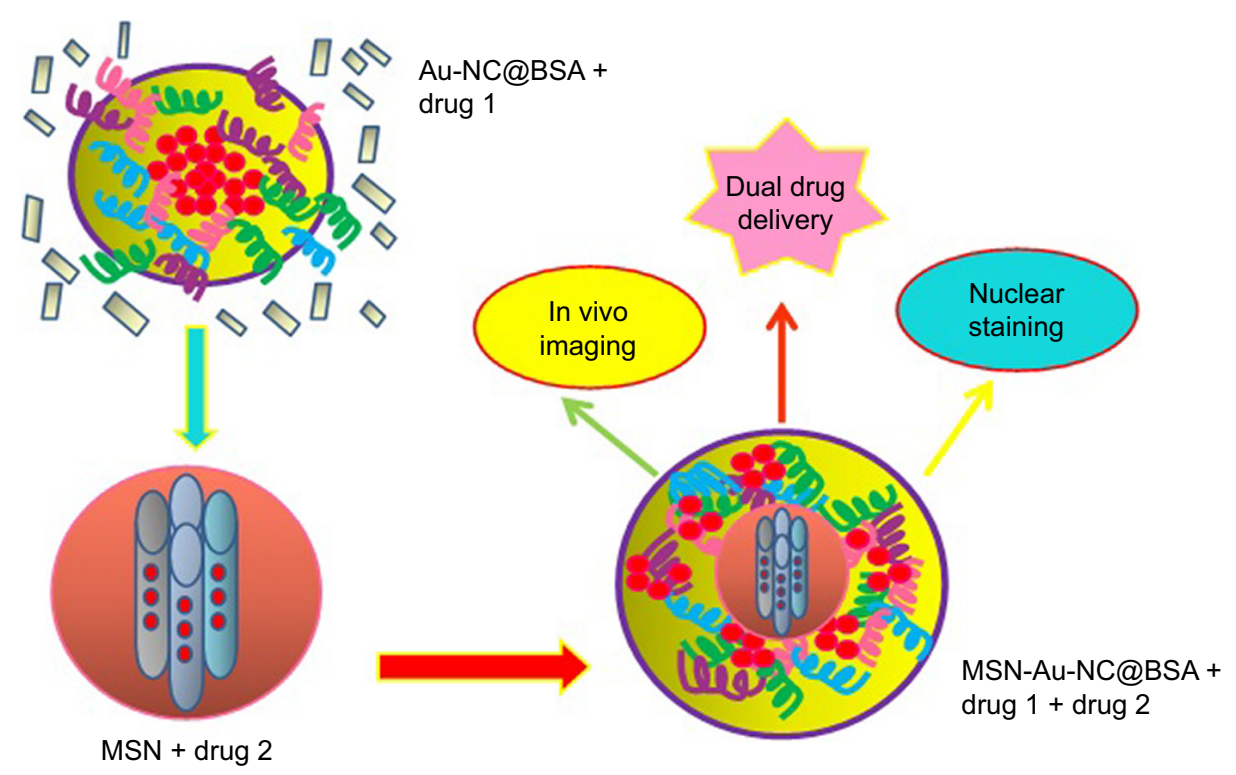

Figure 3 Protein-gold cluster-capped mesoporous silica NPs for high drug loading, autonomous gemcitabine/DOX codelivery, and in vivo tumor imaging. Note: Data from Croissant et al. ${ }^{58}$

Abbreviations: Au-NCs, gold nanoclusters; DOX, doxorubicin; MSN, mesoporous silica nanoparticle; NPs, nanoparticles. 


\section{Modification of Au-NPs for Dau delivery}

Leukemia, which results in death in many cases around the world, is a cancer type that usually involves blood cells and bone marrow. One of the common types of child cancer is known as acute lymphoblastic leukemia (ALL), and chemotherapy is one of the most used ALL treatments in children. One of the most common chemotherapeutic drugs is Dau, which is an anthracycline antibiotic. Dau clinical administration has been limited, owing to its cumulative cardiotoxicity mainly in children. ${ }^{85}$

Taghdisi et al, in their study, fabricated sgc8, an aptamer for protein tyrosine kinase-7 (PTK7), for Dau-specific delivery to Molt- 4 cells. The results of flow cytometry revealed that the aptamer-Dau complex was internalized effectively to Molt-4 cells but not to U266 cells. They observed no cell viability significant change between the Dau and aptamer-Dau complex treated with Molt- 4 cells. ${ }^{85}$

In another study, Danesh et al modified polyvalent aptamer (PA)-Dau-Au-NP complexes and assessed their efficacy in human ALL T-cells (Molt-4, target). They loaded efficiently Dau $(10.5 \mu \mathrm{M})$ onto $1 \mathrm{~mL}$ of PA-modified $\mathrm{Au}-$ NPs. Dau was released from the fabricated complex in a $\mathrm{pH}-$ sensitive manner and faster release was observed at $\mathrm{pH}$ 5.5. The obtained flow cytometry analysis results indicated that the PA-Dau-Au-NP complex was internalized into target cells, but not into nontarget cells. The MTT assay results were consistent with the internalization data. PA-Dau-AuNP complexes had less cytotoxicity in B lymphocyte human myeloma cells (U266, nontarget), and more cytotoxicity in Molt-4 cells, compared with both Dau alone and the Apt-Dau-Au-NP complexes. The PA-Dau-Au-NP complex cytotoxicity was effectively antagonized using the antisense of PA. The designed system of drug delivery had efficient drug loading and tumor targeting capabilities, drug release in a pH-dependent manner, and demonstrated controllable Dau delivery to tumor cells. ${ }^{86}$

As shown in Figure 4, Manivasagan et $\mathrm{al}^{78}$ synthesized biocompatible Au-NPs by using CHI oligosaccharide (COS) as a stabilizing and reducing agent and loaded subsequently with PTX to show their use in the drug delivery and PAI of MDA-MB-231 cells. PTX-COS Au-NPs were of spherical shape with sustained and $\mathrm{pH}$-dependent drug release profiles and strong cytotoxic effects against MDA-MB-231 cells. The process was apoptosis induction with an improved generation of ROS. Fluorescence microscopy and flow cytometry were used to prove the cellular internalization of PTX-COS Au-NPs. The synthesized complex was also evaluated for optical CAs for PAI. ${ }^{61}$

Moreover, Figure 5 shows an overall scheme for the biosynthesized Au-NPs using COS, subsequent PTX loading on COS-stabilized gold nanoparticles (COS Au-NPs), and a possible mechanism for the cellular uptake of PTX-loaded COS-stabilized gold nanoparticles (PTX-COS Au-NPs) in MDA-MB-231 cancer cells. In addition, these biosynthesized Au-NPs were able to attach to biological macromolecules and were loaded subsequently with PTX to show their use in anticancer drug delivery and PAI of cancer cells. ${ }^{61}$

In the work by Rezaei et al, an electrochemical ultrasensitive DOX impedance immunosensor was investigated by the immobilization of a monoclonal antibody (mAb) on Au-NPs associated with a thiol base sol-gel (TBSol-Gel)-modified gold electrode. The fabricated immunosensor capability for DOX determination in spiked human serum and urine samples was examined, and the obtained results demonstrated that the immunosensor can be used as a good tool for DOX determination in biological samples. ${ }^{87}$

\section{Surface plasmon resonance of Au-NPs}

The increasing availability of nanostructures with highly controlled optical properties in the nanometer size range has created widespread interest in their use in biotechnological systems for diagnostic applications and biological imaging. ${ }^{88}$ Quantum dots are widely used and studied for diagnostic applications and biological imaging due to their unique sizedependent fluorescence properties, ${ }^{89}$ but potential human

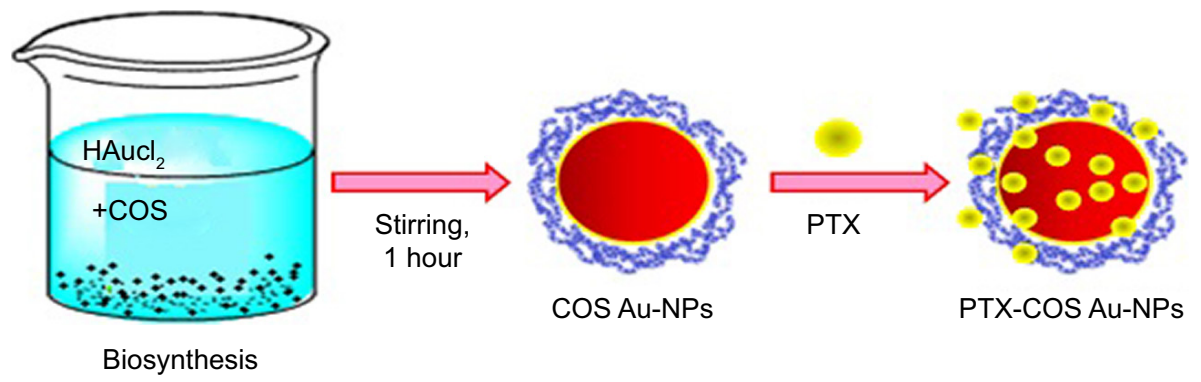

Figure 4 PTX-loaded chitosan oligosaccharide-stabilized Au-NPs as novel agents for drug delivery and photoacoustic imaging of cancer cells. Note: Data from Manivasagan et al. ${ }^{78}$

Abbreviations: Au-NPs, gold nanoparticles; COS, chitosan oligosaccharide; PTX, paclitaxel. 


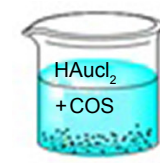

Biosynthesis

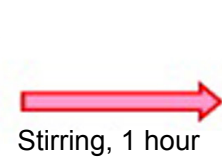

Stirring, 1 hour

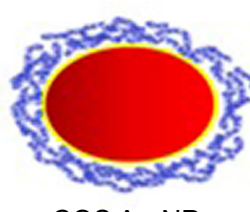

COS Au-NPs
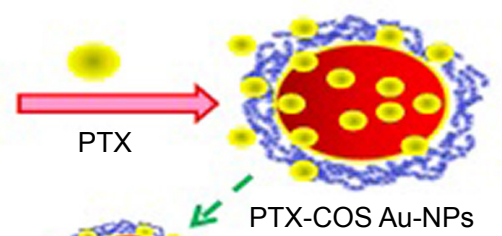

に PTX-COS Au-NPs
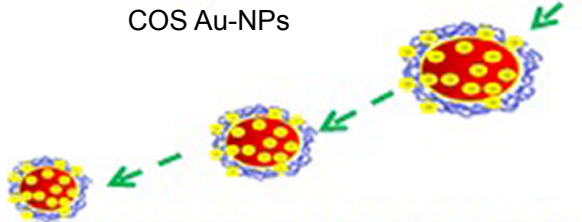

6

\section{IIIIIIIIIIIIIIIIIIIIIIIIIIIIIIIIIIIIIIIIIIII}

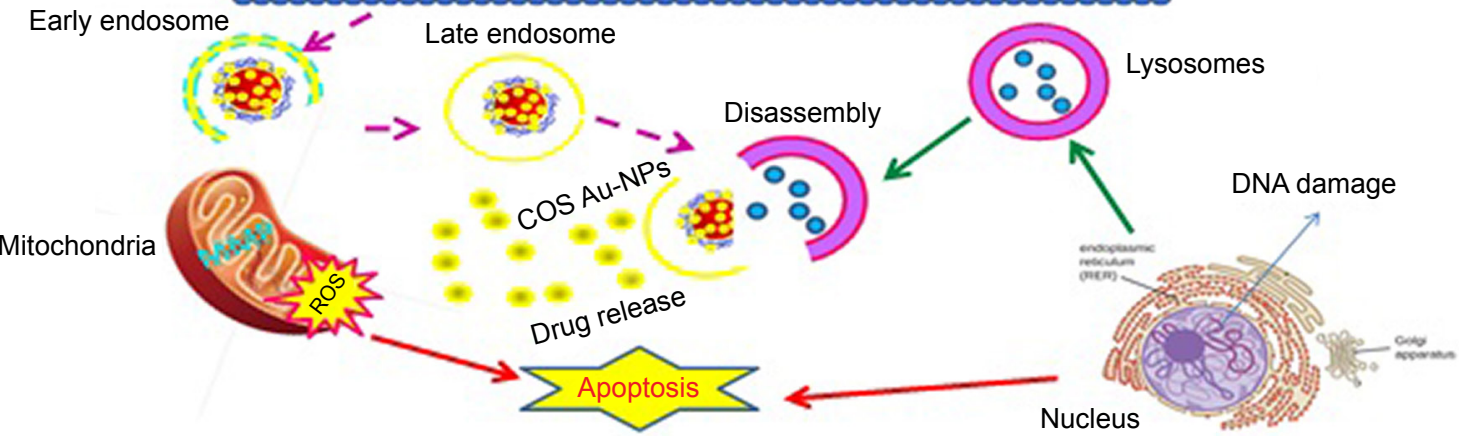

Figure 5 Overall scheme for the biosynthesis of Au-NPs using COS, subsequent loading of PTX on COS-stabilized Au-NPs (COS Au-NPs), and the possible mechanism for the cellular uptake of loaded COS-stabilized Au-NPs (PTX-COS Au-NPs) in MDA-MB-23I cancer cells.

Note: Data from Manivasagan et al. ${ }^{78}$

Abbreviations: Au-NPs, gold nanoparticles; COS, chitosan oligosaccharide; PTX, paclitaxel.

toxicity and cytotoxicity of the semiconductor material are two major problems for its in vitro and in vivo application. Colloidal Au-NPs have become an alternative consideration due to their ease of preparation, ready bioconjugation, and potential noncytotoxicity.$^{90}$ Immuno-Au-NPs conjugated to antibodies have provided excellent detection qualities for cellular labeling using electron microscopy. Au-NPs have the ability to resonantly scatter visible and near-infrared light upon the excitation of their surface plasmon oscillation. Au-NPs have several advantages for cellular imaging compared with other agents. They scatter light intensely, and they are much brighter than chemical fluorophores. They do not photobleach, and they can be easily detected in as low as a $10^{-16} \mathrm{M}$ concentration. Sokolov described the scattering of anti-EGFR/Au-NPs for cervical cancer when stimulated with a laser at a single wavelength. Irradiation with a laser will only scatter light that is close to the laser wavelength used. ${ }^{91}$

\section{MRI contrast agent}

Small-sized IO NPs can exhibit superparamagnetic behavior with very weak magnetic interactions and good dispersion; when an external field is applied, they will undergo transition from a superparamagnetic state to a ferrimagnetic state. This distinctive feature together with other properties, such as a large surface area and high biocompatibility, makes them promising nanoagents for highly sensitive MRI, targeted drug delivery, multimodal diagnosis, and treatment of a number of diseases and biological sensing. ${ }^{92,93}$ The general requirements of magnetic hyperthermia agents are mainly related to their $M \mathrm{~s}$, surface coating, and size. These parameters strongly affect both the magnetic behavior of the particles and their stability, biocompatibility, and biodistribution. ${ }^{94,95}$ Magnetic resonance-guided focused ultrasound surgery (MRgFUS), as a promising noninvasive ultrasound thermal treatment for soft tissue lesions, has been utilized in the treatment of prostate, kidney, and liver cancer. In particular, there is precise control of beam direction, and ongoing feedback is provided to detail temperature changes at and around the treated tissue in MRgFUS ${ }^{96}$ Despite its great promise in the noninvasive treatment of cancers, MRgFUS is currently limited by the insensitivity of MRI for visualization of small tumors, low efficiency of in vivo ultrasonic energy deposition, and damage to surrounding tissues. In 2017, Wang et al reported the development of an active targeting nano-sized theranostic superparamagnetic iron oxide (SPIO) platform for significantly increasing the imaging sensitivity and energy deposition efficiency using a clinical MRgFUS system. The surfaces of these PEGylated SPIO NPs were decorated with anti-EGFR mAbs for the targeted delivery to lung cancer with EGFR overexpression. The potential 
of these targeted nano-theranostic agents for MRI and MRgFUS ablation was evaluated in vitro and in vivo in a rat xenograft model of human lung cancer (H460). Compared with nontargeting PEGylated SPIO NPs, the anti-EGFR mAb-targeted PEGylated SPIO NPs demonstrated a better targeting capability to $\mathrm{H} 460$ tumor cells and greatly improved the MRI contrast at the tumor site. Meanwhile, their results showed that the targeting NPs, as synergistic agents, could significantly enhance the efficiency for in vivo ultrasonic energy deposition in MRgFUS. Moreover, they demonstrated that a series of MR methods including T2-weighted image, T1-weighted image (T1WI), diffusion-weighted imaging, and contrast-enhanced T1WI imaging could be utilized to noninvasively and conveniently monitor the therapeutic efficacy in rat models by MRgFUS. ${ }^{97}$ In particular, the metal ferrite $\mathrm{NP} \mathrm{MFe}_{2} \mathrm{O}_{4}(\mathrm{M}=\mathrm{Mn}, \mathrm{Co}, \mathrm{Ni}$, etc) represents an important class of magnetic ternary compound NPs, which have found wide biomedical applications, mostly as highly sensitive MRI nanoprobes for the in vivo and noninvasive detection of clinically important biological targets. ${ }^{98}$ Recent advances in this field have revealed that the ultrasmall magnetite NPs with sizes $<5 \mathrm{~nm}$ can exhibit remarkable and counterintuitive T1 MR enhancement due to their strong size-related effects, in stark contrast to the conventional SPIO-based CA such as Feridex, which is the representative T2 CA. $.99,100$

\section{IO NP conjugates in DDSs}

Magnetic nanoparticles (M-NPs), including the core of IO and its polymeric shell, present an effective carrier for the enhanced tumor delivery of therapeutic agents. The IO core shows that the high magnetic susceptibility enables noninvasive manipulation of M-NPs by magnetic fields. Localized, magnetically assisted capture of blood-borne M-NPs, termed "magnetic targeting", has been shown to enhance drug delivery of subcutaneous tumor lesions in both clinical and preclinical settings. ${ }^{101}$ In order to reduce the tumor metastasis and recurrence, an efficient DDS with local drug release on demand over a prolonged duration in tumors and interstitial tissue is highly desirable, so as to reduce systematic toxicity. Hence, the incorporation of magnetic hyperthermia agents and chemotherapeutic agents into hydrogels has attracted special attention owing to the superiority of an alternating magnetic field, eg, remote controlled, contactless actuation, and deep penetrability. The combination therapy of magnetic hyperthermia and chemotherapy with on-demand drug release reached a much higher therapeutic effect than single therapy without significant side or systematic effects. ${ }^{102}$

The summarized applications of IO NPs/drugs are presented in Table 4.

\section{5-FU release from IO NPs}

Das et al reported a fabrication method for a magnetic gadolinium oxide-IO core, mesoporous silica shell gated with boronic acid functionalized with highly luminescent carbon quantum dots (BNSCQD). They used a porous silica shell as a anticancer drug 5-FU reservoir, whereas the BNSCQD cap played a controller role in drug transportation under a simulated intracellular environment. Based on the experiment

Table 4 Overview of iron oxide nanoparticles/drugs and their applications

\begin{tabular}{|c|c|c|c|}
\hline Nanoparticles & $\begin{array}{l}\text { Drugs/targeting } \\
\text { agent }\end{array}$ & Applications & References \\
\hline Magnetic mesoporous silica gated with doped carbon dot & $5-\mathrm{FU}$ & $\begin{array}{l}\text { Fluorescence imaging of Sla- } \\
\text { overexpressed HePG } 2 \text { cancer cells }\end{array}$ & 103 \\
\hline $\begin{array}{l}\text { Magnetic iron oxide/mesoporous silica nanocomposites } \\
(\mathrm{m}-\mathrm{MCM}-4 \mathrm{I})\end{array}$ & $5-\mathrm{FU}$ & Drug release system & 104 \\
\hline Chitosan-co-PEG/poly(glycerol sebacate)-co-PEG-coated iron oxide & $5-\mathrm{FU}$ & $\begin{array}{l}\text { Carrier for 5-FU anticancer, HT29 } \\
\text { cell line }\end{array}$ & 105 \\
\hline $\begin{array}{l}\text { Polylactic-co-glycolic acid (PLGA) NPs as 5-FU carriers with/without } \\
\text { iron oxide core }\end{array}$ & $5-\mathrm{FU}$ & $\begin{array}{l}\text { Carrier for } 5 \text {-FU anticancer human } \\
\text { colon cancer cell line HT29 }\end{array}$ & 106 \\
\hline PLGA-coated magnetite nanographene oxide & $5-\mathrm{FU}$ & Rabbit plasma & 107 \\
\hline $\begin{array}{l}\text { Polycaprolactone }(\mathrm{PCL}) \text { /chitosan }(\mathrm{CHI}) \text {-coated superparamagnetic } \\
\text { iron oxide nanographene oxide (SPION-NGO) }\end{array}$ & $5-\mathrm{FU}$ & CT26 colon cancer cell line & 108 \\
\hline Magnetic $\mathrm{NPs} \mathrm{Fe}_{3} \mathrm{O}_{4}$ & 5-FU & 7,90 I cancer cells & 119 \\
\hline Magnetic field-sensitive methylcellulose and PCL gels & $5-\mathrm{FU}$ & Targeted and controlled release & 110 \\
\hline B-cyclodextrin-PEG-polyethyleneimine-coated iron oxide NPs & $5-\mathrm{FU}$ & L929 and MCF-7 & 111 \\
\hline Encapsulation of superparamagnetic $\mathrm{Fe}_{3} \mathrm{O}_{4}$ & $5-\mathrm{FU}$ & 7,901 cancer cells & 112 \\
\hline
\end{tabular}


Table 4 (Continued)

\begin{tabular}{|c|c|c|c|}
\hline Nanoparticles & $\begin{array}{l}\text { Drugs/targeting } \\
\text { agent }\end{array}$ & Applications & References \\
\hline Polyglycerol-coated iron oxide NPs & FA & Human cervical carcinoma cell line & 113 \\
\hline Magnetic mesoporous silica NPs & FA & Cancerous HeLa cells & 114 \\
\hline Folate-decorated cobalt ferrite nanoparticles coated with PEG & FA & $\begin{array}{l}\text { HSF I I } 84 \text { (human skin fibroblast } \\
\text { cells) and HeLa (human cervical } \\
\text { cancer cell, FAR+) }\end{array}$ & 115 \\
\hline Iron oxide NPs/hyperbranched polyglycerol & FA & MCF-7 cells & 116 \\
\hline $\begin{array}{l}\text { Iron oxide NP-conjugated chitosan-graft-poly(2-dimethylaminoethyl } \\
\text { methacrylate) }\end{array}$ & FA & $\begin{array}{l}\text { L929 (mouse fibroblast) cell line, } \\
\text { MCF-7 (human breast cancer) cell } \\
\text { line, and MDA-MB-23I (human } \\
\text { breast cancer) cell line }\end{array}$ & 117 \\
\hline Iron oxide NPs & FA & $\begin{array}{l}\text { MRI detection and hyperthermia } \\
\text { treatment of lymph node metastases } \\
\text { of prostate cancer }\end{array}$ & 118 \\
\hline Magnetite@SiO_nanostructures & FA & Human cervical cancer line & 119 \\
\hline Aminosilane MNPs & FA & $\begin{array}{l}\text { Colorectal cancer and an animal } \\
\text { model of cancer xenograft }\end{array}$ & 120 \\
\hline Magnetic NPs/PEG & FA & $\begin{array}{l}\text { Human cervix epitheloid carcinoma } \\
\text { HeLa cells, human breast carcinoma } \\
\text { cells MCF-7 and MDA-MB435 }\end{array}$ & 121 \\
\hline Starch/ZnO-coated iron oxide NPs & FA & $\begin{array}{l}\text { Human lymphocytes, HepG2, and } \\
\text { MCF-7 cell lines }\end{array}$ & 122 \\
\hline $\mathrm{Fe}_{3} \mathrm{O}_{4}-\mathrm{ZnO}$ hybrid NPs & FA & $\begin{array}{l}\text { Photodynamic therapy, human } \\
\text { epithelial colorectal adenocarcinoma } \\
(\text { Caco-2) cells }\end{array}$ & 123 \\
\hline $\begin{array}{l}\text { Poly(N-isopropylacrylamide) hydrogel core/superparamagnetic } \\
\text { magnetite NPs }\end{array}$ & FA & Cervical cancer cell line (HeLa) & 124 \\
\hline Polyethylenimine superparamagnetic iron oxide NPs & FA & $\begin{array}{l}\text { MRI and PD-LI siRNA delivery for } \\
\text { gastric cancer }\end{array}$ & 125 \\
\hline Iron oxide NPs/functionalized with FA and rhodamine & FA & $\begin{array}{l}\text { Cell proliferation assay on HeLa } \\
\text { cells }\end{array}$ & 126 \\
\hline Bovine serum albumin-coated superparamagnetic $\gamma$ - $\mathrm{Fe}_{2} \mathrm{O}_{3} \mathrm{NPs}$ & FA & U25I & 127 \\
\hline $\begin{array}{l}\text { Amine group immobilized iron oxides, } \mathrm{Fe}_{3} \mathrm{O}_{4}-\mathrm{NH}_{2} \text {, attached on the } \\
\text { surface of self-assembled triblock copolymer, poly[(acrylic acid)- } \\
\text { block-( } \mathrm{N} \text {-isopropylacrylamide)-block-(acrylic acid)] }\end{array}$ & FA & MCF-7 & 128 \\
\hline $\begin{array}{l}\text { Basic cobalt ferrite }\left(\mathrm{CoFe}_{2} \mathrm{O}_{4}\right) \text { particles covalently bonded with a } \\
\text { photosensitizer }\end{array}$ & FA & PC-3 & 129 \\
\hline $\begin{array}{l}\text { Carboxylated quercetin conjugated to superparamagnetic iron } \\
\text { oxide NPs modified by (3-aminopropyl) triethoxysilane, FA, and } \\
\text { carboxylated PEG }\end{array}$ & FA & MCF-7, HeLa, and A549 & 130 \\
\hline $\begin{array}{l}\text { Superparamagnetic iron oxide functionalized with (3-aminopropyl) } \\
\text { triethoxysilane and PEG }\end{array}$ & FA & U87 & $|3|$ \\
\hline $\begin{array}{l}\text { Superparamagnetic iron oxide NPs coated with chitosan and } \\
\text { FA-conjugated chitosan }\end{array}$ & FA & MCF-7 & 132 \\
\hline FA-targeted iron oxide $\left(\mathrm{Fe}_{3} \mathrm{O}_{4}\right) \mathrm{NPs}$ & FA & $\begin{array}{l}\text { Human serous ovarian cell line } \\
\text { (Skov-3) }\end{array}$ & 133 \\
\hline $\begin{array}{l}\text { Iron oxide NPs/chitosan, FA/loaded with aqueous poorly soluble } \\
\text { quercetin }\end{array}$ & FA & PC-3 and MCF-7 & 134 \\
\hline $\begin{array}{l}\text { Magnetic mesoporous silica NPs/CuS nanocrystals/photothermal } \\
\text { agent/PEG }\end{array}$ & FA & HeLa & 135 \\
\hline PEGylated PEG bis(carboxymethyl ether)/ $\mathrm{Fe}_{3} \mathrm{O}_{4} \mathrm{NPs}$ & DOX & Cancer therapy & 136 \\
\hline
\end{tabular}


Table 4 (Continued)

\begin{tabular}{|c|c|c|c|}
\hline Nanoparticles & $\begin{array}{l}\text { Drugs/targeting } \\
\text { agent }\end{array}$ & Applications & References \\
\hline $\mathrm{Fe}_{3} \mathrm{O}_{4} @ \mathrm{MoS}_{2}$ nanocubes & DOX & $\begin{array}{l}\text { Human breast cancer xenograft in } \\
\text { nude mice }\end{array}$ & 137 \\
\hline DOX-loaded dendritic- $\mathrm{Fe}_{3} \mathrm{O}_{4}$ supramolecular NPs & DOX & $\begin{array}{l}\text { Magnetic drug targeting and tumor } \\
\text { regression in spheroid murine } \\
\text { melanoma model }\end{array}$ & 138 \\
\hline PEGylated cubic $\mathrm{Fe}_{3} \mathrm{O}_{4} \mathrm{NPs}$ & DOX & $\begin{array}{l}\text { Mouse skin fibrosarcoma } \\
\text { (WEHI-164) cells }\end{array}$ & 139 \\
\hline $\begin{array}{l}\text { Magnetite NPs hydrophilized by nonionic surfactant pluronic } \\
\text { FI27-polyethylene-polypropylene oxide polymer }\end{array}$ & DOX & $\begin{array}{l}\mathrm{LNCaP} \text { and } \mathrm{PC}-3 \text { prostate cancer } \\
\text { cell lines }\end{array}$ & 140 \\
\hline Chitosan-functionalized $\mathrm{Fe}_{3} \mathrm{O}_{4} \mathrm{NPs}$ & DOX & $\begin{array}{l}\text { Ovarian cancer cell (SK-OV-3) and } \\
\text { breast cancer cell line (MCF-7) }\end{array}$ & $|4|$ \\
\hline $\mathrm{Fe}_{3} \mathrm{O}_{4} \mathrm{NPs}$ coated with poly(N-isopropylacrylamide) & DOX & $\begin{array}{l}\text { Human cervical carcinoma cell line, } \\
\text { MRI }\end{array}$ & 142 \\
\hline $\begin{array}{l}\text { Iron oxide NPs/DOX-loaded calcium phosphate/arginylglycylaspartic } \\
\text { acid }\end{array}$ & DOX & T24 bladder cancer cells & 143 \\
\hline $\begin{array}{l}\text { Sodium alginate-polyvinyl alcohol-bovine serum albumin-coated } \\
\mathrm{Fe}_{3} \mathrm{O}_{4} \mathrm{NPs}\end{array}$ & DOX & HepG2 and L02 cells & 144 \\
\hline FA-conjugated PEG-coated MNPs & DOX & HeLa cell line & 145 \\
\hline $\mathrm{Fe}_{3} \mathrm{O}_{4}$-inositol hexaphosphate & DOX & MG-63 cell line & 146 \\
\hline Genipin-cross-linked iron (III) oxide/polyetherimide NPs & DOX & HeLa cell line & 147 \\
\hline Polyvinyl alcohol hydrogel grafted by modified $\mathrm{Fe}_{3} \mathrm{O}_{4} \mathrm{NPs}$ & DOX & DOX delivery & 148 \\
\hline Cucurbit[7]uril-modified iron-oxide NPs & DOX & $\begin{array}{l}\text { HeLa cells, MCF-7, A2780, Dox- } \\
\text { resistant A2780, and HEK } 293 \text { cells }\end{array}$ & 149 \\
\hline Dextran-coated superparamagnetic iron oxide NPs & DOX & $\begin{array}{l}\text { Human pancreatic carcinoma cell } \\
\text { lines MIA PaCa-2 }\end{array}$ & 150 \\
\hline Dual-targeted NPs loaded with DOX and MNPs & DOX & MCF-7 & 151 \\
\hline Superparamagnetic iron oxide NPs & DOX & LO2 and HepG2 & 152 \\
\hline $\begin{array}{l}\text { Liposome-capped core-shell mesoporous silica-coated } \\
\text { superparamagnetic iron oxide NPs }\end{array}$ & DOX & MCF-7 and U87 & 153 \\
\hline $\mathrm{Fe}_{3} \mathrm{O}_{4} \mathrm{NP}$-capped mesoporous silica & DOX & HepG2 & 154 \\
\hline Superparamagnetic $\mathrm{Fe}_{3} \mathrm{O}_{4} \mathrm{NPs}$ & DOX & L929 and HeLa & 155 \\
\hline Azobis[N-(2-carboxyethyl)-2-methylpropionamidine] & DOX & MCF-7 & 156 \\
\hline Superparamagnetic iron oxide NPs & DOX & U25I & 157 \\
\hline Iron oxide@meso-silica NPs & DOX & HeLa cell line & 158 \\
\hline $\begin{array}{l}\text { Polyacrylic acid-functionalized } \mathrm{Fe}_{3} \mathrm{O}_{4} \mathrm{NPs} \text { are conjugated with FA } \\
\text { through peptide bonding }\end{array}$ & DOX & HeLa cell line & 159 \\
\hline $\begin{array}{l}\mathrm{Fe}_{3} \mathrm{O}_{4} \text { encapsulated in inner aqueous phase and hydrophobic drug } \\
\text { (curcumin) }\end{array}$ & DOX & HeLa cell line & 160 \\
\hline PEG carboxyl-poly(e-caprolactone)-modified MNPs & PTX & $\begin{array}{l}\text { Mouse H22 hepatocarcinoma cells } \\
\text { (H22), human embryonic kidney } \\
\text { cells (HEK293T), and hepatoma } \\
\text { carcinoma cell (Hep G2) }\end{array}$ & 161 \\
\hline Loaded magnetic NPs modified with methoxy PEG-lysine-oleic acid & PTX & $\begin{array}{l}\text { Liver, left kidney, and right kidney } \\
\text { cell }\end{array}$ & 162 \\
\hline $\mathrm{Fe}_{3} \mathrm{O}_{4} \cdot$ dopamine-bovine serum albumin/hyaluronic acid & PTX & MRI & 163 \\
\hline TAT peptide-conjugated magnetic PLA-PEG nanocapsules & PTX & $\begin{array}{l}\text { Human lung adenocarcinoma } \\
\text { epithelial cells A549 }\end{array}$ & 164 \\
\hline $\begin{array}{l}\text { Peptide H7K(R2)2-modified, theranostic liposome- } \\
\text { superparamagnetic iron oxide NPs }\end{array}$ & PTX & $\begin{array}{l}\mathrm{H} 7 \mathrm{~K}(\mathrm{R} 2) 2 \text { in MDA-MB-23 I cell line, } \\
\mathrm{MRI}\end{array}$ & 165 \\
\hline
\end{tabular}


Table 4 (Continued)

\begin{tabular}{|l|l|l|l|}
\hline Nanoparticles & $\begin{array}{l}\text { Drugs/targeting } \\
\text { agent }\end{array}$ & Applications & References \\
\hline $\mathrm{Fe}_{3} \mathrm{O}_{4} \mathrm{NPs}$ into porous isoreticular metal & PTX & HeLa and NIH3T3 & 166 \\
\hline Methoxy PEG-poly(D,L-lactide-co-glycolide)(MPEG-PLGA) & PTX & HeLa and A549 & 167 \\
\hline Superparamagnetic polymer microcontainers & Dau & $\begin{array}{l}\text { PH-sensitive controlled release } \\
\text { mechanism }\end{array}$ & 168 \\
\hline Dau-loaded MNPs & Dau & $\begin{array}{l}\text { Human chronic myelogenous } \\
\text { leukemia cells (K562 cells) }\end{array}$ & 169 \\
\hline Magnetic iron oxide NPs coloaded with Dau and 5-bromotetrandrin & Dau & Human leukemia K562/A02 cells & I70 \\
\hline $\mathrm{PLA}_{\text {multiwalled carbon nanotubes } \mathrm{Fe}_{3} \mathrm{O}_{4} \text { composite nanofibers }}$ & Dau & Leukemia cancer cells & $17 \mathrm{I}$ \\
\hline $\mathrm{ZnFe}_{2} \mathrm{O}_{4} \mathrm{NPs}$ & Dau & HeLa cells & $\mathrm{I72}$ \\
\hline
\end{tabular}

Abbreviations: Dau, Daunorubicin; DOX, doxorubicin; 5-FU, 5-fluorouracil; FA, folic acid; FAR, folic acid receptor; MNPs, magnetic nanoparticles; NPs, nanoparticles; PEG, polyethylene glycol; PLA, polylactic acid; PTX, paclitaxel.

results, the fabricated construct is a promising theranostic material because of its advantages in stimuli-responsive drug release, significant optical imaging, and MRI. A drug release experiment under various $\mathrm{pH}$ values and in the presence of the competitive binding ligand SLa clearly showed excellent responsiveness of the BNSCQD-capped MSN hybrid system toward dual stimuli. ${ }^{103}$

In another study, Egodawatte et al evaluated three different solvents (dimethyl sulfoxide, water, and water/acetone) for loading of 5-FU into magnetic $\mathrm{IO} /$ mesoporous silica nanocomposites (m-MCM-41) with and without functionalization of aminopropyl. Their findings showed that the 5-FU loading and release characteristics from m-MCM-41 depended on the polarity of the solvent and the surface functionalization of the host. The greater capacity of hydrogen bonding in the amine functionalized with 5-FU accounted for a lower release of 5-FU when water/acetone and water were applied as loading solvents. ${ }^{104}$

As demonstrated in Figure 6, Naghizadeh et al tested polyglycerol sebacate-PEG/CHI-PEG-coated IO (PGS-PEG/ CS-PEG@ $\left.\mathrm{Fe}_{3} \mathrm{O}_{4}\right)$ NPs as a carrier for 5-FU in a controlled release study in vitro. They measured the ability of PGSPEG/CS-PEG@ $\mathrm{Fe}_{3} \mathrm{O}_{4} \mathrm{NPs}$, to deliver 5-Fu by analyzing the drug release rate in physiological simulated media. The data obtained from the study in the physiological fluids clearly showed that drug release from PGS-PEG NPs as a control was remarkably faster than that observed when PGS-PEG/CS-PEG NPs were used. In their study, PGS-PEG/CS-PEG@ $\mathrm{Fe}_{3} \mathrm{O}_{4}$ NPs were developed under mild conditions to improve the biocompatibility and drug targeting of NPs for cancer therapy. In order to prepare CS-PEG for bonding PEG to the hydroxyl group of $\mathrm{CS}$, the amine groups at the $\mathrm{C} 2$ position of the CS were protected using sodium dodecylsulfate (SDS) and then removed simply by dialyzing the precipitation against a Tris solution. To engineer the release of the drug at two different rates, they suggest blending of CS-PEG with PGS-PEG and using this composition as a polymeric shell of M-NPs for drug delivery. This polymeric composition was used as a nanocarrier for solubilizing the poorly soluble anticancer drug 5-FU. Drug-loaded M-NPs were synthesized and its potential for use as a 5-FU carrier for HT29 target delivery was investigated. ${ }^{105}$

Shen et a $\mathrm{l}^{109}$ reported the synthesis of a thermoresponsive system for the release of a drug, which encapsulated the $\mathrm{Fe}_{3} \mathrm{O}_{4}$-NPs and the drug model 5-FU with a thermosensitive polymer poly(N-isopropylacrylamide) (PNIPAM). As the drug release channel, they used mesoporous $\mathrm{SiO}_{2}$, which could enhance the drug loading rate and reduce drug loss.

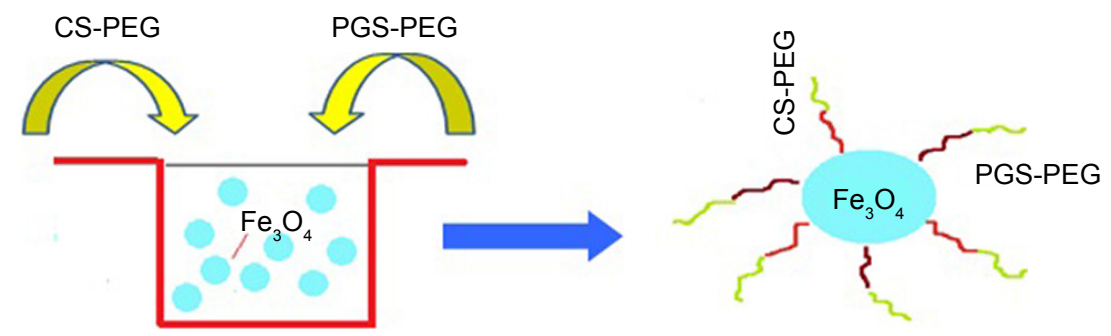

Figure 6 Controlled release of 5-fluorouracil from CS-PEG/PGS-PEG-coated iron oxide.

Note: Data from Naghizadeh et al. ${ }^{105}$

Abbreviations: CS-PEG, chitosan-co-poly(ethylene glycol); PGS-PEG, poly(glycerol sebacate)-co-poly(ethylene glycol). 


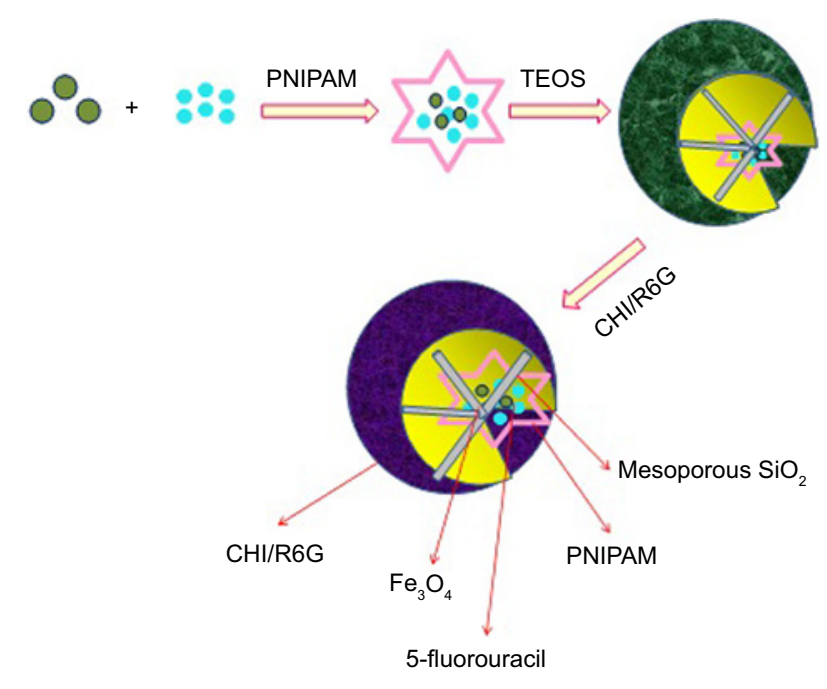

Figure 7 Smart multifunctional magnetic nanoparticle-based drug delivery system for cancer thermo-chemotherapy and intracellular imaging.

Note: Data from Shen et al. ${ }^{109}$

Abbreviations: $\mathrm{CHI}$, chitosan; PNIPAM, poly(N-isopropylacrylamide); TEOS, tetraethyl orthosilicate.

They coated successfully rhodamine $6 \mathrm{G}$ (R6G) and $\mathrm{CHI}$ on the $\mathrm{SiO}_{2}$ spherical surface. The results confirmed the intermolecular interactions of the nanocomposites. R6G is a typical fluorochrome, which is usable in cell imaging. A study using fluorescent imaging by confocal laser scanning microscopy showed that the fabricated nanocomposites $\mathrm{Fe}_{3} \mathrm{O}_{4} / \mathrm{PNIPAM} / 5-\mathrm{Fu} @ \mathrm{mSiO}_{2}-\mathrm{CHI} / \mathrm{R} 6 \mathrm{G}$ could specially target cells of a tumor.

In Figure 7, a drug carrier system synthesis process for $\mathrm{Fe}_{3} \mathrm{O}_{4} / \mathrm{PNIPAM} / 5-\mathrm{Fu} @ \mathrm{mSiO}_{2}-\mathrm{CHI} / \mathrm{R} 6 \mathrm{G}$, which is temperature-responsive at different temperatures in vitro is depicted. In the system for drug delivery, $\mathrm{Fe}_{3} \mathrm{O}_{4}$-NPs were used as the source of magnetism and treatment of hyperthermia. Under the magnetic field and based on the magnetocaloric function of M-NPs, thermoresponsive drug delivery was controllable. The $\mathrm{Fe}_{3} \mathrm{O}_{4} / \mathrm{PNIPAM} / 5-\mathrm{Fu} @ \mathrm{mSiO}_{2}$-CHI/R6G drug carrier showed low cytotoxicity and was usable as a cell imaging agent via a MTT study and images from confocal laser scanning microscopy.

\section{Modification of IO NPs with FA}

Fakhimikabir et al investigated the therapeutic role of FAconjugated, polyglycerol-coated IO NPs on HeLa cell radiosensitivity when irradiated with $6 \mathrm{MeV}$ electron beams. It was observed that the uptake penetration rate for cells treated with FA-PG-SPIONs was more compared with nontargeted NPs. No significant reduction was observed for cell viability based on the data obtained by the trypan blue dye exclusion test for all groups in comparison with the control group. The results showed that the radiation dose increment in the presence of different concentrations of the NPs increased radiosensitivity. The highest concentration of FA-PG-SPIONs led to the most radiosensitivity. It was shown that FA-PG-SPION at higher concentrations with a combination of $6 \mathrm{MeV}$ electron beams could enhance HeLa cell radiosensitization. ${ }^{113}$

In another study, Avedian et al prepared a drug delivery nanocarrier to cells of tumors based on magnetic mesoporous silica NPs (MMSNs), including an $\mathrm{IO}\left(\mathrm{Fe}_{3} \mathrm{O}_{4}\right)$ core coated with mesoporous silica and a pH-responsive shell of poly(ethyleneimine)-conjugated FA. They loaded erlotinib as an anticancer drug and evaluated the release profile at different $\mathrm{pH}$ values over 4 days. The obtained hemolysis confirmed a negligible hemolytic activity of the prepared NPs. Moreover, they did not observe any significant toxicity for erlotinib-free MMSNs, while the erlotinib-loaded MMSNs inhibited the proliferation of HeLa cells. In addition, FA-labeled NPs had a higher cytotoxic effect on cancerous HeLa cells. Accordingly, the obtained results revealed a system with controlled targeted drug delivery to decrease the side effects of anticancer drugs. ${ }^{114}$ The sequential steps for the preparation of $\mathrm{Fe}_{3} \mathrm{O}_{4} @ \mathrm{MSN} / \mathrm{PEI}-$ FA are shown in Figure 8.

Zhang et al proposed FA-conjugated $\mathrm{Fe}_{3} \mathrm{O}_{4} \mathrm{NPs}$ as a CA for T2 negative for MRI to accurately detect ovarian cancer tissues in an intraperitoneal xenograft tumor model. The FAconjugated $\mathrm{Fe}_{3} \mathrm{O}_{4} \mathrm{NPs}(9.2 \pm 1.7 \mathrm{~nm})$ had a low cytotoxicity effect to these human serous ovarian cell line (Skov-3). The cellular uptake results showed the targeting specificity of the FA-targeted $\mathrm{Fe}_{3} \mathrm{O}_{4}$ NPs to Skov-3 cells overexpressing FARs. They suggested that the FA-targeted $\mathrm{Fe}_{3} \mathrm{O}_{4}$ NPs are a promising detection agent for human ovarian carcinoma using MRI and are usable for the treatment of hyperthermal tumors as well. ${ }^{133}$

Patel et al synthesized a FA-conjugated hybrid $\mathrm{Fe}_{3} \mathrm{O}_{4}-$ ZnO NPs (FZ-SFA) and investigated their interactions and photosensitivity with cancerous cells under radiation. For this purpose, silanisation and chemical conjugation of FA to the hybrid $\mathrm{Fe}_{3} \mathrm{O}_{4}-\mathrm{ZnO}$ cores was carried out. The photosensitizer photocatalytic properties were assessed and optimized using methylene blue photodegradation. Moreover, cell viability assessment and effective photoinduced cytotoxicity of NPs were completed using colorectal adenocarcinoma (Caco-2) cells. The subsequent preparation stages are presented schematically in Figure 9. FZ NP surface modification was carried out with silica and the subsequent esterification of FA with N-hydroxysuccinimide. Folate conjugation correlated to a further increase in the magnitude of the negative charge. The presence of unbound carboxylate groups on FA would 


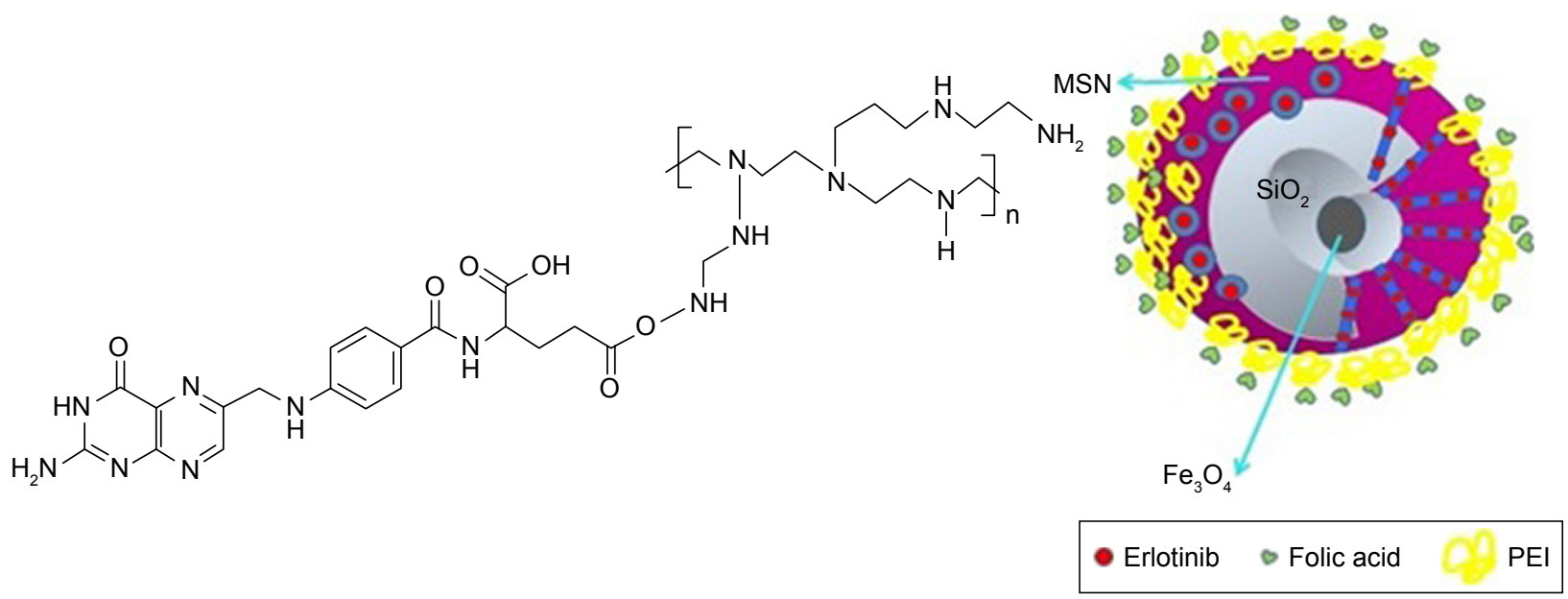

Figure $8 \mathrm{pH}$-sensitive biocompatible mesoporous magnetic nanoparticles labeled with folic acid as an efficient carrier for controlled anticancer drug delivery. Note: Data from Avedian et al. ${ }^{114}$

Abbreviations: MSN, mesoporous silica nanoparticle; PEI, polyethylenimine.

lead to dissociation of hydrogen ions in solution and lead to a negatively charged surface. ${ }^{123}$

\section{Use of IO NPs for DOX delivery}

Ji et al reported a smart $\mathrm{pH}$ and magnetic sensitive DDS based on PEGylated $\mathrm{Fe}_{3} \mathrm{O}_{4}$ superparamagnetic NPs. The citriccoated $\mathrm{Fe}_{3} \mathrm{O}_{4}$ (CIO) NPs were first synthesized and further functionalized to be biocompatible PEG bis(carboxymethyl ether) (COOH-PEG-COOH), thus PEGylated CIO (GCIO) NPs were obtained. DOX was conjugated to the NPs as a model drug via a hydrazone bond. The sphere-like GCIO NPs had significantly strong magnetism with a high drug loading capability ( $\sim 89 \%)$ and a relatively uniform size distribution. Drug release studies revealed that the GCIO-DOX had
$\mathrm{pH}$-responsive drug-release properties. The MTT assay demonstrated that GCIO NPs possessed low cytotoxicity and good physiological stability. Further, cell viability results indicated that the GCIO-DOX showed effective cytotoxicity, although only a bit lower than free DOX. All data obtained indicated that the combined $\mathrm{pH}$-responsive and magnetic multifunction DDS has numerous excellent potential applications for cancer therapy. ${ }^{136}$

In another study, Xie et al used MRI-guided chemophotothermal for human breast cancer xenograft therapy in nude mice using a novel core/shell structure of $\mathrm{Fe}_{3} \mathrm{O}_{4} @$ molybdenum sulfide $\left(\mathrm{MoS}_{2}\right)$ nanocubes (IOMS NCs) via the integration of $\mathrm{MoS}_{2}$ (a typical transition-metal dichalcogenide) films onto IO NCs. After the PEGylation

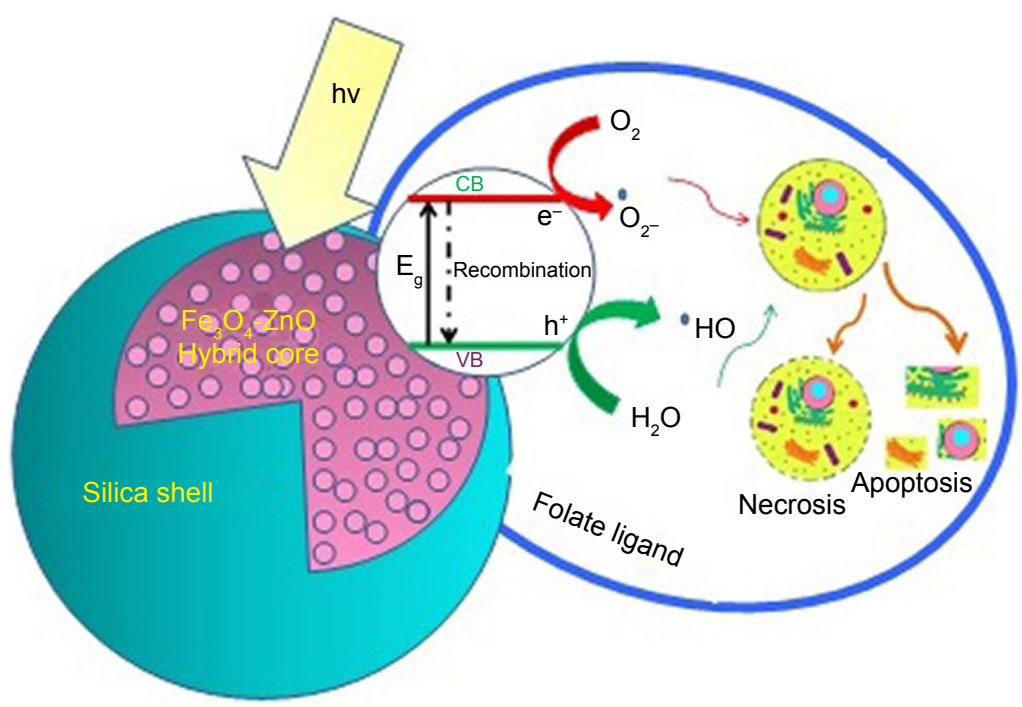

Figure 9 Novel folic acid-conjugated $\mathrm{Fe}_{3} \mathrm{O}_{4}-\mathrm{ZnO}$ hybrid nanoparticles for targeted photodynamic therapy. Note: Data from Kim et al. ${ }^{123}$ 
modification of NCs, such PEGylated NCs were capped with 2-deoxy-d-glucose (2-DG), which is a nonmetabolizable glucose analog and is attractive to resource-hungry cancer cells. The DOX was carried by IOMS-PEG-2DG $\mathrm{NCs}$ as drug carriers. Twenty-four hours after intravenous injection of IOMS-PEG(DOX)-2DG NCs, detection of a tumor site was accomplished by an enhanced T2-weighted MRI signal. A significant increment in temperature was observed in the tumor site by exposure to an NIR $808 \mathrm{~nm}$ laser for 5 minutes at a low power density. They found an efficient inhibition in tumor growth by the chemophotothermal effect. ${ }^{137}$

Based on Figure 10, DOX-loaded PEG and 2-DGmodified $\mathrm{Fe}_{3} \mathrm{O}_{4} / \mathrm{MoS}_{2}$ core/shell NCs as a theranostic nanoplatform (IOMS-PEG(DOX)-2DG NCs) were fabricated using a two-step hydrothermal technique, in which $\mathrm{MoS}_{2}$ were attached to the $\mathrm{Fe}_{3} \mathrm{O}_{4} \mathrm{NCs}$ surface to prepare the $\mathrm{Fe}_{3} \mathrm{O}_{4} @$ $\mathrm{MoS}_{2} \mathrm{NCs}$ (IOMS NCs). DOX acted as chemotherapy agent and 2-DG was used as the active targeting agent to prolong blood circulation time, strengthen the accumulation of IOMS-PEG(DOX)-2DG NCs at the tumor site, and uptake increment in cancer cells. Under NIR laser radiation and external magnetic fields, IOMS-PEG(DOX)-2DG NCs revealed a significant potential for use in cancer MRI-guided chemo-phototherapy.

\section{Modification of IO NPs for PTX and Dau delivery}

Multifunctional magnetic nanoparticles (MMNPs) have been newly developed for tumor-targeted drug carriers. To address challenges such as nontoxicity, biocompatibility, stability, and targeting efficiency, Li et al reported on the novel drug delivery PEG carboxyl-poly(E-caprolactone)-modified MMNP (PEG-PCCL-MNP), suitable for magnetic targeting. The size of the PEG-PCCL-MMNP was $79.6 \mathrm{~nm}$. PEG-PCCLMMNP showed good biocompatibility and little in vitro or in vivo cytotoxicity, as well as effective, tumor-specific cell targeting for drug delivery when an external magnetic field was applied. Based on their results, PEG-PCCL-MMNP is a potential biocompatible candidate for tumor-specific targeting drug vehicles for hydrophobic drugs. ${ }^{161}$

Chatzipavlidis et al produced magnetic pH-sensitive microcontainers. Figure 11 presents the preparation process of the $\mathrm{Fe}_{3} \mathrm{O}_{4}$ poly(N,N0-methylenebis(acrylamide)comathacrylic acid) (P(MBAAm-co-MAA)) microcontainers and the chemical structure of Dau by a four-step process: 1) the fabrication of citrate-modified MNPs using the coprecipitation technique, 2) encapsulation of MNPs in noncrosslinked poly(methacrylic acid) (PMAA) microspheres leads to a core/shell structure, 3 ) synthesis of a P(MBAAm-co-MAA) layer on the magnetic PMAA microsphere surface in order to

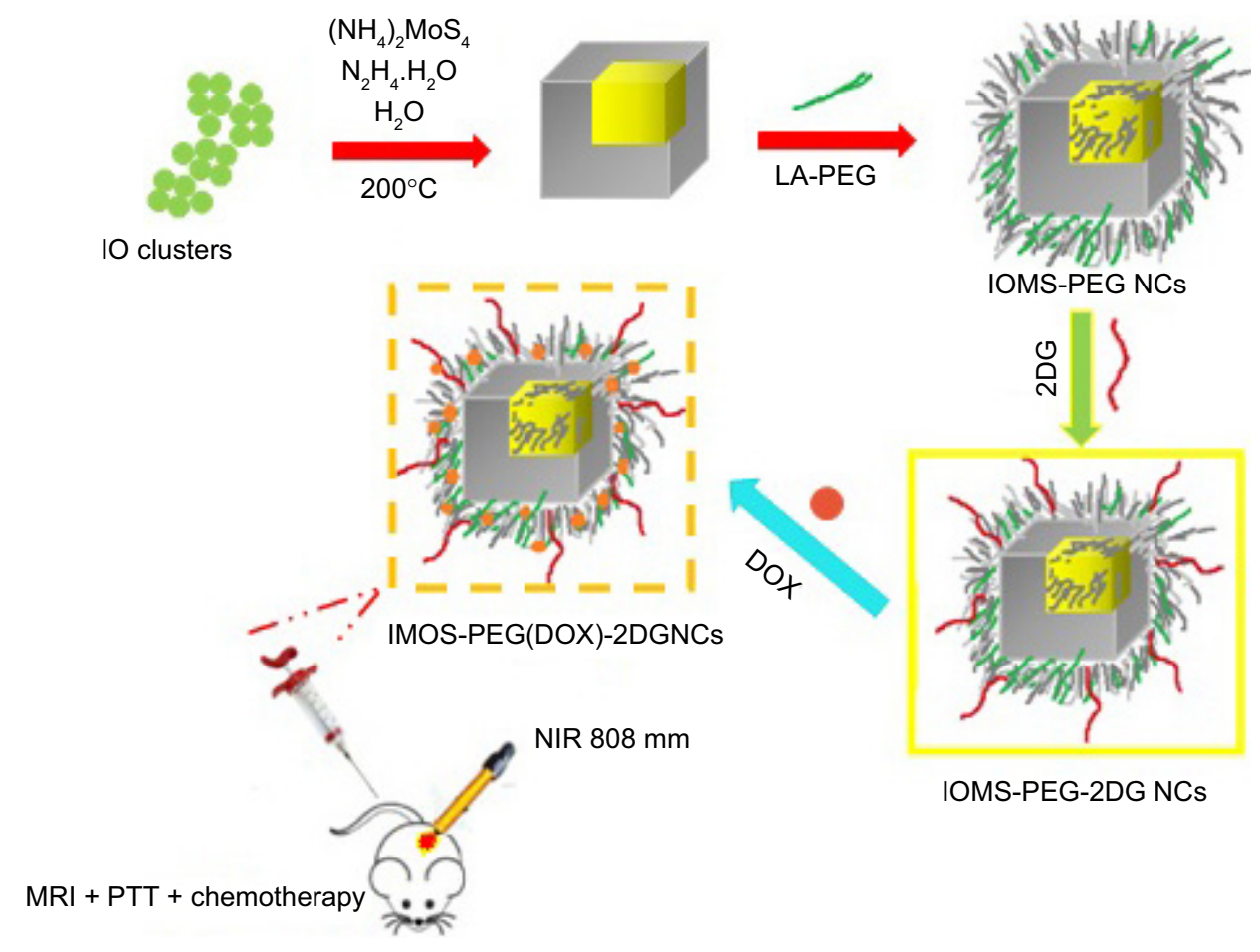

Figure 10 DOX-loaded $\mathrm{Fe}_{3} \mathrm{O}_{4} @ \mathrm{MoS}_{2}$-PEG-2DG nanocubes as a theranostic platform for MRI-guided chemo-photothermal therapy of breast cancer. Note: Data from Xie et al. ${ }^{137}$

Abbreviations: DOX, doxorubicin; IO, iron oxide; IOMS, $\mathrm{Fe}_{3} \mathrm{O}_{4} @$ molybdenum sulfide; NCs, nanoclusters; PEG, polyethylene glycol; PTT, photothermal therapy. 


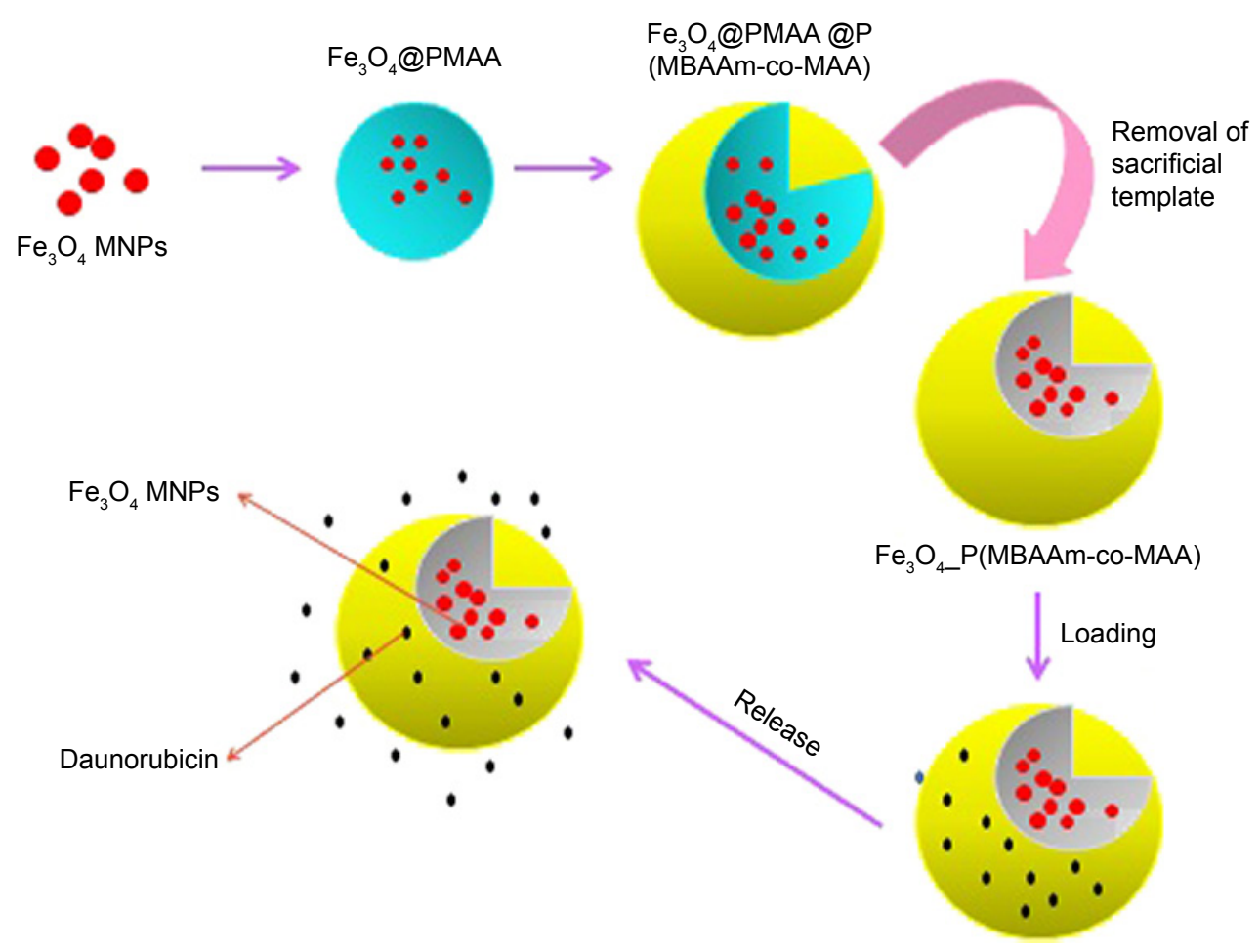

Figure I I Sacrificial template-directed fabrication of superparamagnetic polymer microcontainers for the $\mathrm{pH}$-activated controlled release of Dau. Note: Data from Chatzipavlidis et al. ${ }^{168}$

Abbreviations: MNPs, magnetic nanoparticles; PMAA, poly(methacrylic acid); P(MBAAm-co-MAA), poly(N,N0-methylenebis(acrylamide)-comathacrylic acid).

synthesize a trilayer hybrid microsphere, and 4) the removal of the PMAA layer in ethanol and formation of a stable P(MBAAm-co-MAA) microcontainer with MNPs entrapped inside the formed cavity. This simple process leads to the superparamagnetic formation of $\mathrm{pH}$-sensitive microcontainers. The magnetic $\mathrm{pH}$-sensitive microcontainers were loaded with Dau and investigated with respect to the rate of release at different $\mathrm{pH}$ values for their functional evaluation as a controlled release system. ${ }^{168}$

As highlighted in this review, there has been significant interest and research conducted on Au-NPs and iron NPs for imaging, therapeutic, and drug delivery applications. Their biologically relevant size, ability to easily functionalize with biomolecules, and chemotherapeutic agents aid in their ability to improve therapeutic delivery and noninvasive disease diagnostics. In order for their successful use in biomedical applications, long-term cytotoxicity and genotoxicity of $\mathrm{Au}-\mathrm{NPs}$ and $\mathrm{Fe}_{3} \mathrm{O}_{4} \mathrm{NPs}$ should be evaluated. Nevertheless, the accomplishments in this review demonstrate the significant impact that nanotechnology has had on the biomedical field.

\section{Conclusion}

The poor stability of conventional drugs in biological fluids, their enzymatic degradation, and difficulties in securing their penetration through some barrier or the nuclei of cells are some of the unfavorable attributes of existing technologies. The development of metal NPs has been greatly accelerated over the past decade by advances in nanotechnology and molecular cell biology. Various formulations have been developed to diagnose and treat diseases for which conventional therapy has shown limited efficacy. Iron and Au-NPs have come to the forefront as a promising new vehicle for drug delivery. Control of the manner, place, and timing of release of the payload are vital in drug and gene delivery systems. As we move forward, more effective characterization tools are needed to better understand their behavior in the body. Moreover, questions about metal NP elimination and long-term toxicity remain barriers to clinical entry. Once these concerns are addressed, metal NPs will move closer to clinical application, improving the diagnosis, treatment, and monitoring of our most unmanageable diseases. A conceptual understanding of biological responses to nanomaterials is needed for their future safe development and application in drug delivery. Moreover, a strong collaboration between those working in drug delivery and particle toxicology is necessary for the exchange of concepts, methods, and expertise. Gold and IO NPs have emerged as promising scaffolds for drug and small molecule delivery, providing a useful complement to more traditional delivery vehicles. Their high surface area, combination of low inherent toxicity, 
and tunable stability provide them with unique attributes that should enable new delivery strategies. The key issue that needs to still be addressed is the particle surface engineering for optimizing properties such as nonimmunogenicity and bioavailability.

\section{Disclosure}

The authors report no conflicts of interest in this work.

\section{References}

1. Smith RC, Riollano M, Leung A, Hammond PT. Layer-by-layer platform technology for small-molecule delivery. Angew Chem Int Ed. 2009; 48:8974-8977.

2. Vineis P, Wild CP. Global cancer patterns: causes and prevention. Lancet. 2014;383(9916):549-557.

3. Wang S, Deng H, Huang P, et al. Real-time self-tracking of an anticancer small molecule nanodrug based on colorful fluorescence variations. RSC Advances. 2016;6(15):12472-12478.

4. Makadia HK, Siegel SJ. Poly lactic-co-glycolic acid (PLGA) as biodegradable controlled drug delivery carrier. Polymers. 2011;3:1377-1397.

5. Bhattarai N, Gunn J, Zhang M. Chitosan-based hydrogels for controlled, localized drug delivery. Adv Drug Deliv Rev. 2010;62(1):83-99.

6. Venturoli D, Rippe B. Ficoll and dextran vs. globular proteins as probes for testing glomerular permselectivity: effects of molecular size, shape, charge, and deformability. Am J Physiol Renal Physiol. 2005;288(4): F605-F613.

7. Matsumura Y, Maeda H. A new concept for macromolecular therapeutics in cancer chemotherapy: mechanism of tumoritropic accumulation of proteins and the antitumor agent SMANCS. Cancer Res. 1986; 46(12 Pt 1):6387-6392.

8. Chen ZG. Small-molecule delivery by nanoparticles for anticancer therapy. Trends Mol Med. 2010;16(12):594-602.

9. Brown SD, Nativo P, Smith JA, et al. Gold nanoparticles for the improved anticancer drug delivery of the active component of oxaliplatin. J Am Chem Soc. 2010;132(13):4678-4684.

10. Dobson J. Magnetic nanoparticles for drug delivery. Drug Dev Res. 2006;67(1):55-60.

11. Ghosh P, Han G, De M, Kim CK, Rotello VM. Gold nanoparticles in delivery applications. Adv Drug Deliv Rev. 2008;60(11):1307-1315.

12. Chithrani DB. Nanoparticles for improved therapeutics and imaging in cancer therapy. Recent Pat Nanotechnol. 2010;4(3):171-180.

13. Bumb A, Regino CA, Perkins MR, et al. Preparation and characterization of a magnetic and optical dual-modality molecular probe. Nanotechnology. 2010;21(17):175704.

14. Pascu SI, Arrowsmith RL, Bayly SR, Brayshaw S, Hu Z. Towards nanomedicines: design protocols to assemble, visualize and test carbon nanotube probes for multi-modality biomedical imaging. Phil Trans Math Phys Eng Sci. 2010;368(1924):3683-3712.

15. Golchin K, Golchin J, Ghaderi S, et al. Gold nanoparticles applications: from artificial enzyme till drug delivery. Artif Cells Nanomed Biotechnol. 2018;46(2):250-254.

16. Shenoy D, Fu W, Li J, et al. Surface functionalization of gold nanoparticles using hetero-bifunctional poly(ethylene glycol) spacer for intracellular tracking and delivery. Int J Nanomed. 2006;1(1):51-58.

17. Daraee H, Eatemadi A, Abbasi E, Fekri Aval S, Kouhi M, Akbarzadeh A. Application of gold nanoparticles in biomedical and drug delivery. Artif Cells Nanomed Biotechnol. 2016;44(1):410-422.

18. Lai MK, Chang CY, Lien YW, Tsiang RC. Application of gold nanoparticles to microencapsulation of thioridazine. J Control Release. 2006;111(3):352-361.

19. O'Neal DP, Hirsch LR, Halas NJ, Payne JD, West JL. Photo-thermal tumor ablation in mice using near infrared-absorbing nanoparticles. Cancer Lett. 2004;209(2):171-176.
20. Jiang X, Feng D-Q, Liu G, Fan D, Wang W. A fluorescent switch sensor for detection of anticancer drug and ctDNA based on the glutathione stabilized gold nanoclusters. Sensors Actuators B Chem. 2016;232:276-282.

21. Safwat MA, Soliman GM, Sayed D, Attia MA. Gold nanoparticles enhance 5-fluorouracil anticancer efficacy against colorectal cancer cells. Int J Pharm. 2016;513(1-2):648-658.

22. Schmoll HJ, Twelves C, Sun W, et al. Effect of adjuvant capecitabine or fluorouracil, with or without oxaliplatin, on survival outcomes in stage III colon cancer and the effect of oxaliplatin on post-relapse survival: a pooled analysis of individual patient data from four randomised controlled trials. Lancet Oncol. 2014;15(13):1481-1492.

23. Arias JL, Ruiz MA, López-Viota M, Delgado ÁV. Poly(alkylcyanoacrylate) colloidal particles as vehicles for antitumour drug delivery: a comparative study. Colloids Surf B Biointer. 2008;62(1):64-70

24. Sanap GS, Mohanta GP. Development of miconazole nitrate controlled release formulations based on SLN and NLC for topical delivery. Int J Pharm Pharm Sci. 2014;6:393-399.

25. Khallaf RA, Salem HF, Abdelbary A. 5-Fluorouracil shell-enriched solid lipid nanoparticles (SLN) for effective skin carcinoma treatment. Drug Deliv. 2016;23(9):3452-3460.

26. Ross JF, Chaudhuri PK, Ratnam M. Differential regulation of folate receptor isoforms in normal and malignant tissues in vivo and in established cell lines. physiologic and clinical implications. Cancer. 1994;73(9):2432-2443.

27. Ngernyuang N, Seubwai W, Daduang S, Boonsiri P, Limpaiboon T, Daduang J. Targeted delivery of 5-fluorouracil to cholangiocarcinoma cells using folic acid as a targeting agent. Mater Sci Eng C Mater Biol Appl. 2016;60:411-415.

28. Manivasagan $\mathrm{P}, \mathrm{Oh} \mathrm{J}$. Marine polysaccharide-based nanomaterials as a novel source of nanobiotechnological applications. Int J Biol Macromol. 2016;82:315-327.

29. Venkatpurwar V, Shiras A, Pokharkar V. Porphyran capped gold nanoparticles as a novel carrier for delivery of anticancer drug: in vitro cytotoxicity study. Int J Pharm. 2011;409(1-2):314-320.

30. Lima D, Calaça GN, Viana AG, Pessôa CA. Porphyran-capped gold nanoparticles modified carbon paste electrode: a simple and efficient electrochemical sensor for the sensitive determination of 5-fluorouracil. Appl Surf Sci. 2018;427:742-753.

31. Hsiao PF, Anbazhagan R, Hsiao-Ying C, Vadivelmurugan A, Tsai H-C. Thermoresponsive polyamic acid-conjugated gold nanocarrier for enhanced light-triggered 5-fluorouracil release. RSC Advances. 2017; 7(14):8357-8365.

32. Nivethaa EAK, Dhanavel S, Stephen A. Chitosan stabilized Ag-Au nanoalloy for colorimetric sensing and 5-fluorouracil delivery. Int $J$ Biol Macromol. 2017;95:862-872.

33. Salem DS, Sliem MA, El-Sesy M, Shouman SA, Badr Y. Improved chemophotothermal therapy of hepatocellular carcinoma using chitosan-coated gold nanoparticles. J Photochem Photobiol B Biol. 2018;182:92-99.

34. Safwat MA, Soliman GM, Sayed D, Attia MA. Fluorouracil-loaded gold nanoparticles for the treatment of skin cancer: development, in Vitro characterization, and in Vivo evaluation in a mouse skin cancer xenograft model. Mol Pharm. 2018;15(6):2194-2205.

35. Zhang Z, Jia J, Lai Y, Ma Y, Weng J, Sun L. Conjugating folic acid to gold nanoparticles through glutathione for targeting and detecting cancer cells. Bioorg Med Chem. 2010;18(15):5528-5534.

36. SamadianH,Hosseini-Nami S, Kamrava SK, GhaznaviH, Shakeri-Zadeh A. Folate-conjugated gold nanoparticle as a new nanoplatform for targeted cancer therapy. J Cancer Res Clin Oncol. 2016;142(11):2217-2229.

37. Zhou B, Yang J, Peng C, et al. PEGylated polyethylenimine-entrapped gold nanoparticles modified with folic acid for targeted tumor CT imaging. Colloids Surf B Biointerfaces. 2016;140:489-496.

38. Kumar SSD, Mahesh A, Antoniraj MG, Rathore HS, Houreld NN, Kandasamy R. Cellular imaging and folate receptor targeting delivery of gum kondagogu capped gold nanoparticles in cancer cells. Int J Biol Macromol. 2018;109:220-230. 
39. Malekmohammadi S, Hadadzadeh H, Farrokhpour H, Amirghofran Z. Immobilization of gold nanoparticles on folate-conjugated dendritic mesoporous silica-coated reduced graphene oxide nanosheets: a new nanoplatform for curcumin $\mathrm{pH}$-controlled and targeted delivery. Soft Matter. 2018;14(12):2400-2410.

40. Feng J, Chen L, Xia Y, et al. Bioconjugation of gold nanobipyramids for SERS detection and targeted photothermal therapy in breast cancer. ACS Biomater Sci Eng. 2017;3(4):608-618.

41. Guo J, O'Driscoll CM, Holmes JD, Rahme K. Bioconjugated gold nanoparticles enhance cellular uptake: a proof of concept study for siRNA delivery in prostate cancer cells. Int J Pharm. 2016;509(1-2): $16-27$.

42. Devendiran RM, Chinnaiyan S, Yadav NK, et al. Facile synthesis and evaluation of quercetin reduced and dextran sulphate stabilized gold nanoparticles decorated with folic acid for active targeting against breast cancer. RSC Advances. 2016;6(39):32560-32571.

43. Garay LB, Ortega FM, Méndez-Sanchez SC. Use in vitro of gold nanoparticles functionalized with folic acid as a photothermal agent on treatment of HeLa cells. J Mexican Chem Soc. 2018;62(1):10.

44. Yen HJ, Young YA, Tsai TN, et al. Positively charged gold nanoparticles capped with folate quaternary chitosan: synthesis, cytotoxicity, and uptake by cancer cells. Carbohydr Polym. 2018;183:140-150.

45. Zeinizade E, Tabei M, Shakeri-Zadeh A, et al. Selective apoptosis induction in cancer cells using folate-conjugated gold nanoparticles and controlling the laser irradiation conditions. Artif Cells Nanomed Biotechnol. 2018;46(supp 1):1026-1038.

46. Keyvan Rad J, Mahdavian AR, Khoei S, Shirvalilou S. Enhanced photogeneration of reactive oxygen species and targeted photothermal therapy of C6 glioma brain cancer cells by folate-conjugated gold-photoactive polymer nanoparticles. ACS Appl Mater Interfaces. 2018;10(23):19483-19493.

47. Du B, Gu X, Han X, et al. Lipid-coated gold nanoparticles functionalized by folic acid as gene vectors for targeted gene delivery in vitro and in vivo. ChemMedChem. 2017;12(21):1768-1775.

48. Santiago T, Devaux RS, Kurzatkowska K, Espinal R, Herschkowitz JI, Hepel M. Surface-enhanced Raman scattering investigation of targeted delivery and controlled release of gemcitabine. Int J Nanomedicine. 2017;12:7763-7776.

49. Li Volsi A, Scialabba C, Vetri V, Cavallaro G, Licciardi M, Giammona G. Near-infrared light responsive folate targeted gold nanorods for combined photothermal-chemotherapy of osteosarcoma. ACS Appl Mater Interfaces. 2017;9(16):14453-14469.

50. Vijayashree IS, Niranjana P, Prabhu G, Sureshbabu VV, Manjanna J. Conjugation of $\mathrm{Au}$ nanoparticles with chlorambucil for improved anticancer activity. J Cluster Sci. 2017;28(1):133-148.

51. Wang H, Li S, Zhang L, et al. Tunable fabrication of folic acid-Au@, poly(acrylic acid)/mesoporous calcium phosphate Janus nanoparticles for CT imaging and active-targeted chemotherapy of cancer cells. Nanoscale. 2017;9(38):14322-14326.

52. Jesna KK, Ilanchelian M. Photophysical changes of thionine dye with folic acid capped gold nanoparticles by spectroscopic approach and its in vitro cytotoxicity towards A-549 lung cancer cells. $J$ Mol Liq. 2017;242:1042-1051.

53. Ghaznavi H, Hosseini-Nami S, Kamrava SK, et al. Folic acid conjugated PEG coated gold-iron oxide core-shell nanocomplex as a potential agent for targeted photothermal therapy of cancer. ArtifCells Nanomed Biotechnol. 2017;4:1-11.

54. Manivasagan P, Bharathiraja S, Bui NQ, et al. Doxorubicin-loaded fucoidan capped gold nanoparticles for drug delivery and photoacoustic imaging. Int J Biol Macromol. 2016;91:578-588.

55. Ramalingam V, Varunkumar K, Ravikumar V, Rajaram R. Target delivery of doxorubicin tethered with PVP stabilized gold nanoparticles for effective treatment of lung cancer. Sci Rep. 2018;8(1):3815.

56. Du Y, Xia L, Jo A, et al. Synthesis and evaluation of doxorubicin-loaded gold nanoparticles for tumor-targeted drug delivery. Bioconjug Chem. 2018;29(2):420-430.
57. Devendiran RM, Chinnaiyan S, Yadav NK, et al. Green synthesis of folic acid-conjugated gold nanoparticles with pectin as reducing/stabilizing agent for cancer theranostics. RSC Advances. 2016;6(35):29757-29768.

58. Croissant JG, Zhang D, Alsaiari S, et al. Protein-gold clusters-capped mesoporous silica nanoparticles for high drug loading, autonomous gemcitabine/doxorubicin co-delivery, and in-vivo tumor imaging. J Control Release. 2016;229:183-191.

59. Tsai LC, Hsieh HY, Lu KY, Wang SY, Mi FL. EGCG/gelatindoxorubicin gold nanoparticles enhance therapeutic efficacy of doxorubicin for prostate cancer treatment. Nanomedicine (Lond). 2016;11(1):9-30.

60. Mukherjee S, Sau S, Madhuri D, et al. Green synthesis and characterization of monodispersed gold nanoparticles: toxicity study, delivery of doxorubicin and its bio-distribution in mouse model. J Biomed Nanotechnol. 2016;12(1):165-181.

61. Suarasan S, Focsan M, Potara M, et al. Doxorubicin-incorporated nanotherapeutic delivery system based on gelatin-coated gold nanoparticles: formulation, drug release, and multimodal imaging of cellular internalization. ACS Appl Mater Interfaces. 2016;8(35):22900-22913.

62. Borker S, Pokharkar V. Engineering of pectin-capped gold nanoparticles for delivery of doxorubicin to hepatocarcinoma cells: an insight into mechanism of cellular uptake. Artif Cells Nanomed Biotechnol. 2018;1:1-10.

63. Tu T-Y, Yang S-J, Wang C-H, Lee S-Y, Shieh M-J. Optical Methods for Tumor Treatment and Detection: Mechanisms and Techniques in Photodynamic Therapy XXVII. International Society for Optics and Photonics; 2018;104760Z.

64. Shabana AM, Mondal UK, Alam MR, et al. pH-sensitive multiligand gold nanoplatform targeting carbonic anhydrase IX enhances the delivery of doxorubicin to hypoxic tumor spheroids and overcomes the hypoxia-induced chemoresistance. ACS Appl Mater Interfaces. 2018;10(21):17792-17808.

65. Lee CS, Kim H, Yu J, et al. Doxorubicin-loaded oligonucleotide conjugated gold nanoparticles: a promising in vivo drug delivery system for colorectal cancer therapy. Eur J Med Chem. 2017;142:416-423.

66. Lin W, Zhang X, Qian L, Yao N, Pan Y, Zhang L. Doxorubicin-loaded unimolecular Micelle-Stabilized gold nanoparticles as a theranostic nanoplatform for tumor-targeted chemotherapy and computed tomography imaging. Biomacromolecules. 2017;18(12):3869-3880.

67. Liu Y, Wang S, Zhang R. Composite poly(lactic acid)/chitosan nanofibrous scaffolds for cardiac tissue engineering. Int J Biol Macromol. 2017;103:1130-1137.

68. Iram S, Zahera M, Khan S, et al. Gold nanoconjugates reinforce the potency of conjugated cisplatin and doxorubicin. Colloids Surf B Biointerfaces. 2017;160:254-264.

69. Maney V, Singh M. An in vitro assessment of novel chitosan/bimetallic PtAu nanocomposites as delivery vehicles for doxorubicin. Nanomedicine (Lond). 2017;12(21):2625-2640.

70. Wang L, Jang G, Ban DK, et al. Multifunctional stimuli responsive polymer-gated iron and gold-embedded silica nano golf balls: nanoshuttles for targeted on-demand theranostics. Bone Res. 2017;5:17051.

71. Yang Y, Lin Y, Di D, et al. Gold nanoparticle-gated mesoporous silica as redox-triggered drug delivery for chemo-photothermal synergistic therapy. J Colloid Interface Sci. 2017;508:323-331.

72. Khutale GV, Casey A. Synthesis and characterization of a multifunctional gold-doxorubicin nanoparticle system for $\mathrm{pH}$ triggered intracellular anticancer drug release. Eur J Pharm Biopharm. 2017;119: 372-380.

73. Munir I, Ajmal S, Shah MR, Ahmad A, Hameed A, Ali SA. Protein-drug nanoconjugates: finding the alternative proteins as drug carrier. Int $J$ Biol Macromol. 2017;101:131-145.

74. Kim H, Nguyen VP, Manivasagan P, et al. Doxorubicin-fucoidan-gold nanoparticles composite for dual-chemo-photothermal treatment on eye tumors. Oncotarget. 2017;8(69):113719-113733.

75. Gao YY, Chen H, Zhou YY, et al. Intraorgan targeting of gold conjugates for precise liver cancer treatment. ACS Appl Mater Interfaces. 2017;9(37):31458-31468 
76. Sun Y, Wang Q, Chen J, et al. Temperature-sensitive gold nanoparticlecoated pluronic-PLL nanoparticles for drug delivery and chemophotothermal therapy. Theranostics. 2017;7(18):4424-4444.

77. Curtis LT, England CG, Wu M, Lowengrub J, Frieboes HB. An interdisciplinary computational/experimental approach to evaluate drug-loaded gold nanoparticle tumor cytotoxicity. Nanomedicine (Lond). 2016;11(3): 197-216.

78. Manivasagan P, Bharathiraja S, Bui NQ, Lim IG, Oh J. Paclitaxel-loaded chitosan oligosaccharide-stabilized gold nanoparticles as novel agents for drug delivery and photoacoustic imaging of cancer cells. Int J Pharm. 2016;511(1):367-379.

79. Li F, Zhou X, Zhou H, et al. Reducing both Pgp overexpression and drug efflux with anti-cancer gold-paclitaxel nanoconjugates. PLoS One. 2016;11(7):e0160042.

80. Jeong Y, Kim ST, Jiang Y, et al. Nanoparticle-dendrimer hybrid nanocapsules for therapeutic delivery. Nanomedicine (Lond). 2016;11(12): 1571-1578.

81. Mauro N, Volsi AL, Scialabba C, Licciardi M, Cavallaro G, Giammona G. Photothermal ablation of cancer cells using folate-coated gold/graphene oxide composite. Curr Drug Deliv. 2017;14(3):433-443.

82. Zhang N, Chen H, Liu AY, et al. Gold conjugate-based liposomes with hybrid cluster bomb structure for liver cancer therapy. Biomaterials. 2016;74:280-291.

83. Zhang M, Yilmaz T, Boztas AO, et al. A multifunctional nanoparticulate theranostic system with simultaneous chemotherapeutic, photothermal therapeutic, and MRI contrast capabilities. RSC Advances. 2016;6(33):27798-27806.

84. Shu Y, Yin H, Rajabi M, et al. RNA-based micelles: a novel platform for paclitaxel loading and delivery. J Control Release. 2018;276:17-29.

85. Taghdisi SM, Danesh NM, Lavaee P, et al. Double targeting, controlled release and reversible delivery of daunorubicin to cancer cells by polyvalent aptamers-modified gold nanoparticles. Mater Sci Eng C Mater Biol Appl. 2016;61:753-761.

86. Danesh NM, Lavaee P, Ramezani M, Abnous K, Taghdisi SM. Targeted and controlled release delivery of daunorubicin to T-cell acute lymphoblastic leukemia by aptamer-modified gold nanoparticles. Int J Pharm. 2015;489(1-2):311-317.

87. Rezaei B, Askarpour N, Ensafi AA. A novel sensitive doxorubicin impedimetric immunosensor based on a specific monoclonal antibodygold nanoaprticle-sol-gel modified electrode. Talanta. 2014;119:164-169.

88. El-Sayed IH, Huang X, El-Sayed MA. Surface plasmon resonance scattering and absorption of anti-EGFR antibody conjugated gold nanoparticles in cancer diagnostics: applications in oral cancer. Nano Lett. 2005;5(5):829-834.

89. Bruchez M, Moronne M, Gin P, Weiss S, Alivisatos AP. Semiconductor nanocrystals as fluorescent biological labels. Science. 1998; 281(5385):2013-2016.

90. West JL, Halas NJ, Hirsch LR. Optically-active nanoparticles for use in therapeutic and diagnostic method. United States patent US 6,530,944. 2003.

91. Yguerabide J, Yguerabide EE. Light-scattering submicroscopic particles as highly fluorescent analogs and their use as tracer labels in clinical and biological applications. Anal Biochem. 1998;262(2):157-176.

92. Liu XL, Yang Y, Ng CT, et al. Magnetic vortex nanorings: a new class of hyperthermia agent for highly efficient in vivo regression of tumors. Adv Mater. 2015;27(11):1939-1944.

93. Liu XL, Fan HM, Yi JB, et al. Optimization of surface coating on Fe3O4 nanoparticles for high performance magnetic hyperthermia agents. J Mater Chem. 2012;22(17):8235-8244.

94. Chang L, Liu XL, di Fan D, et al. The efficiency of magnetic hyperthermia and in vivo histocompatibility for human-like collagen proteincoated magnetic nanoparticles. Int J Nanomedicine. 2016;11:1175.

95. Xue W, Liu Y, Zhang N, et al. Effects of core size and PEG coating layer of iron oxide nanoparticles on the distribution and metabolism in mice. Int J Nanomedicine. 2018;13:5719-5731.
96. Gianfelice D, Khiat A, Amara M, Belblidia A, Boulanger Y. MR imaging-guided focused US ablation of breast cancer: histopathologic assessment of effectiveness - initial experience. Radiology. 2003;227(3):849-855.

97. Wang Z, Qiao R, Tang N, et al. Active targeting theranostic iron oxide nanoparticles for MRI and magnetic resonance-guided focused ultrasound ablation of lung cancer. Biomaterials. 2017;127:25-35.

98. Zhang H, Li L, Liu XL, et al. Ultrasmall ferrite nanoparticles synthesized via dynamic simultaneous thermal decomposition for high-performance and multifunctional $T_{1}$ magnetic resonance imaging contrast agent. ACS Nano. 2017;11(4):3614-3631.

99. Taboada E, Rodríguez E, Roig A, Oró J, Roch A, Muller RN. Relaxometric and magnetic characterization of ultrasmall iron oxide nanoparticles with high magnetization. Evaluation as potential T1 magnetic resonance imaging contrast agents for molecular imaging. Langmuir. 2007;23(8):4583-4588.

100. Tromsdorf UI, Bruns OT, Salmen SC, Beisiegel U, Weller H. A highly effective, nontoxic $\mathrm{T} 1 \mathrm{Mr}$ contrast agent based on ultrasmall PEGylated iron oxide nanoparticles. Nano Lett. 2009;9:4434-4440.

101. Chertok B, David AE, Yang VC. Polyethyleneimine-modified iron oxide nanoparticles for brain tumor drug delivery using magnetic targeting and intra-carotid administration. Biomaterials. 2010;31(24): 6317-6324.

102. Xue W, Liu X-L, Ma H, et al. AMF responsive DOX-loaded magnetic microspheres: transmembrane drug release mechanism and multimodality postsurgical treatment of breast cancer. J Mater Chem. 2018;6(15):2289-2303.

103. Das RK, Pramanik A, Majhi M, Mohapatra S. Magnetic mesoporous silica gated with doped carbon dot for site-specific drug delivery, fluorescence, and MR imaging. Langmuir. 2018;34(18):5253-5262.

104. Egodawatte S, Dominguez S, Larsen SC. Solvent effects in the development of a drug delivery system for 5-fluorouracil using magnetic mesoporous silica nanoparticles. Microporous Mesoporous Mater. 2017;237:108-116

105. Naghizadeh S, Hassanzadeh Nemati N, Hassani Najafabadi A, Niknejad H, Khani M-M. Controlled release of fluorouracil (5-FU) from chitosan-co-poly(ethylene glycol)/poly(glycerol sebacate)-copoly(ethylene glycol)-coated iron oxide. Int J Polymer Mater Polymer Biomater. 2018;67(4):212-220.

106. Eynali S, Khoei S, Khoee S, Esmaelbeygi E. Evaluation of the cytotoxic effects of hyperthermia and 5-fluorouracil-loaded magnetic nanoparticles on human colon cancer cell line HT-29. Int J Hyperther. 2017;33(3):327-335

107. Mohammadi Gazestani A, Khoei S, Khoee S, Emamgholizadeh Minaei S, Motevalian M. In vivo evaluation of the combination effect of near-infrared laser and 5-fluorouracil-loaded PLGA-coated magnetite nanographene oxide. Artif Cells Nanomed Biotechnol. 2018; 10:1-9.

108. Asadi L, Shirvalilou S, Khoee S, Khoei S. Cytotoxic effect of 5-fluorouracil-loaded polymer-coated magnetite nanographene oxide combined with radiofrequency. Anticancer Agents Med Chem. 2018; 18(8):1148-1155.

109. Shen B, Ma Y, Yu S, Ji C. Smart multifunctional magnetic nanoparticle-based drug delivery system for cancer thermochemotherapy and intracellular imaging. ACS Appl Mater Interfaces. 2016;8(37):24502-24508.

110. Nikjoo D, Aroguz AZ. Magnetic field responsive methylcellulosepolycaprolactone nanocomposite gels for targeted and controlled release of 5-fluorouracil. Int J Polym Mater. 2016;65(8):421-432.

111. Prabha G, Raj V. Formation and characterization of $\beta$-cyclodextrin ( $\beta$-CD)-polyethyleneglycol (PEG)-polyethyleneimine (PEI) coated Fe3O4 nanoparticles for loading and releasing 5-Fluorouracil drug. Biomed Pharmacother. 2016;80:173-182.

112. Shen BB, Gao XC, Yu SY, Ma Y, Ji CH. Fabrication and potential application of a di-functional magnetic system: magnetic hyperthermia therapy and drug delivery. Cryst Eng Comm. 2016;18(7):1133-1138. 
113. Fakhimikabir H, Tavakoli MB, Zarrabi A, Amouheidari A, Rahgozar S. The role of folic acid-conjugated polyglycerol coated iron oxide nanoparticles on radiosensitivity with clinical electron beam $(6 \mathrm{MeV})$ on human cervical carcinoma cell line: in vitro study. $J$ Photochem Photobiol B Biol. 2018;182:71-76.

114. Avedian N, Zaaeri F, Daryasari MP, Akbari Javar H, Khoobi M. $\mathrm{pH}$-sensitive biocompatible mesoporous magnetic nanoparticles labeled with folic acid as an efficient carrier for controlled anticancer drug delivery. J Drug Deliv Sci Techn. 2018;44:323-332.

115. Nasiri M, Hassanzadeh-Tabrizi SA. Synthesis and characterization of folate-decorated cobalt ferrite nanoparticles coated with poly(ethylene glycol) for biomedical applications. J Chin Chem Soc. 2018;65(2):231-242.

116. Mostaghasi E, Zarepour A, Zarrabi A. Folic acid armed Fe3O4-HPG nanoparticles as a safe nano vehicle for biomedical theranostics. J Taiwan Inst Chem Eng. 2018;82:33-41.

117. Anirudhan TS, Christa Binusreejayan J. pH and magnetic field sensitive folic acid conjugated protein-polyelectrolyte complex for the controlled and targeted delivery of 5-fluorouracil. J Ind Eng Chem. 2018;57:199-207.

118. Bonvin D, Bastiaansen JAM, Stuber M, Hofmann H, Mionić Ebersold M, Ebersold MM. Folic acid on iron oxide nanoparticles: platform with high potential for simultaneous targeting, MRI detection and hyperthermia treatment of lymph node metastases of prostate cancer. Dalton Trans. 2017;46(37):12692-12704.

119. Bettini S, Giancane G, Pagano R, et al. A simple approach to synthetize folic acid decorated magnetite $@ \mathrm{SiO}_{2}$ nanostructures for hyperthermia applications. J Mater Chem B. 2017;5(36):7547-7556.

120. Niemirowicz K, Car H, Sadowska A, et al. Pharmacokinetics and anticancer activity of folic acid-functionalized magnetic nanoparticles. J Biomed Nanotech. 2017;13(6):665-677.

121. Allard-Vannier E, Hervé-Aubert K, Kaaki K, et al. Folic acid-capped PEGylated magnetic nanoparticles enter cancer cells mostly via clathrin-dependent endocytosis. Biochim Biophys Acta Gen Subj. 2017; 1861(6):1578-1586.

122. Saikia C, Das MK, Ramteke A, Maji TK. Evaluation of folic acid tagged aminated starch/ZnO coated iron oxide nanoparticles as targeted curcumin delivery system. Carbohydr Polym. 2017;157:391-399.

123. Patel K, Raj BS, Chen Y, Lou X. Novel folic acid conjugated $\mathrm{Fe}_{3} \mathrm{O}_{4}$ $\mathrm{ZnO}$ hybrid nanoparticles for targeted photodynamic therapy. Colloids Surf B Biointerfaces. 2017;150:317-325.

124. Kim H, Jo A, Baek S, et al. Synergistically enhanced selective intracellular uptake of anticancer drug carrier comprising folic acidconjugated hydrogels containing magnetite nanoparticles. Sci Rep. 2017;7(1):41090.

125. Luo X, Peng X, Hou J, Wu S, Shen J, Wang L. Folic acid-functionalized polyethylenimine superparamagnetic iron oxide nanoparticles as theranostic agents for magnetic resonance imaging and PD-L1 siRNA delivery for gastric cancer. Int J Nanomedicine. 2017;12:5331-5343.

126. Ancira-Cortez A, Morales-Avila E, Ocampo-García BE, et al. Preparation and characterization of a tumor-targeting dual-image system based on iron oxide nanoparticles functionalized with folic acid and rhodamine. J Nanomater. 2017;2017(1):1-11.

127. Wang X, Tu M, Tian B, Yi Y, Wei Z, Wei F. Synthesis of tumortargeted folate conjugated fluorescent magnetic albumin nanoparticles for enhanced intracellular dual-modal imaging into human brain tumor cells. Anal Biochem. 2016;512:8-17.

128. Kuo C-Y, Liu T-Y, Hardiansyah A, Chiu W-Y. Magnetically polymeric nanocarriers for targeting delivery of curcumin and hyperthermia treatments toward cancer cells. J Polymer Sci Polymer Chem. 2016;54(17):2706-2713.

129. Choi K-H, Nam K, Malkinski L, Choi E, Jung J-S, Park B. Sizedependent photodynamic anticancer activity of biocompatible multifunctional magnetic submicron particles in prostate cancer cells. Molecules. 2016;21(9):1187.
130. Akal ZÜ, Alpsoy L, Baykal A. Biomedical applications of SPION@ APTES@PEG-folic acid@carboxylated quercetin nanodrug on various cancer cells. Appl Surf Sci. 2016;378:572-581.

131. Akal ZÜ, Alpsoy L, Baykal A. Superparamagnetic iron oxide conjugated with folic acid and carboxylated quercetin for chemotherapy applications. Ceram Int. 2016;42(7):9065-9072.

132. Zarrin A, Sadighian S, Rostamizadeh K, et al. Design, preparation, and in vitro characterization of a trimodally-targeted nanomagnetic onco-theranostic system for cancer diagnosis and therapy. Int J Pharm. 2016;500(1-2):62-76.

133. Zhang H, Li J, Hu Y, Shen M, Shi X, Zhang G. Folic acid-targeted iron oxide nanoparticles as contrast agents for magnetic resonance imaging of human ovarian cancer. J Ovarian Res. 2016;9(1):19.

134. Nandagopal GD, Periyathambi P, Sastry TP. Fabrication of a multifunctional nanocomposite containing INP coated with chitosan coupled with folic acid and loaded with quercetin in diagnosis and its possible treatment of cancer. RSC Advances. 2016;6(101):99514-99523.

135. Gao Z, Liu X, Deng G, et al. $\mathrm{Fe}_{3} \mathrm{O}_{4} @ \mathrm{mSiO}_{2}-\mathrm{FA}-\mathrm{CuS}-\mathrm{PEG}$ nanocomposites for magnetic resonance imaging and targeted chemophotothermal synergistic therapy of cancer cells. Dalton Trans. 2016;45(34):13456-13465.

136. Ji F, Zhang K, Li J, Gu Y, Zhao J, Zhang J. A dual pH/magnetic responsive nanocarrier based on PEGylated $\mathrm{Fe}_{3} \mathrm{O}_{4}$ nanoparticles for doxorubicin delivery. J Nanosci Nanotechnol. 2018;18(7):4464-4470.

137. Xie W, Gao Q, Wang D, et al. Doxorubicin-loaded Fe3O4@MoS2PEG-2DG nanocubes as a theranostic platform for magnetic resonance imaging-guided chemo-photothermal therapy of breast cancer. Nano Research. 2018;11(5):2470-2487.

138. Nigam S, Bahadur D. Doxorubicin-loaded dendritic-Fe $\mathrm{O}_{4}$ supramolecular nanoparticles for magnetic drug targeting and tumor regression in spheroid murine melanoma model. Nanomed Nanotechnol Biol Med. 2018;14:759-768.

139. Dutta B, Shetake NG, Gawali SL, et al. PEG mediated shape-selective synthesis of cubic Fe3O4 nanoparticles for cancer therapeutics. J Alloy Comp. 2018;737:347-355.

140. Nizamov TR, Garanina AS, Grebennikov IS, et al. Effect of iron oxide nanoparticle shape on doxorubicin drug delivery toward LNCaP and PC-3 cell lines. BioNanoScience. 2018;8(1):394- 406.

141. Adimoolam MG, Amreddy N, Nalam MR, Sunkara MV. A simple approach to design chitosan functionalized Fe3O4 nanoparticles for $\mathrm{pH}$ responsive delivery of doxorubicin for cancer therapy. J Magn Magn Mater. 2018;448:199-207.

142. Yar Y, Khodadust R, Akkoc Y, et al. Development of tailored SPIONPNIPAM nanoparticles by ATRP for dually responsive doxorubicin delivery and MR imaging. J Mater Chem. 2018;6(2):289-300.

143. Wang Y-P, Liao Y-T, Liu C-H, et al. Trifunctional $\mathrm{Fe}_{3} \mathrm{O}_{4} / \mathrm{CaP} /$ Alginate core-shell-corona nanoparticles for magnetically guided, pH-responsive, and chemically targeted chemotherapy. ACS Biomater Sci Eng. 2017;3(10):2366-2374.

144. Prabha G, Raj V. Sodium alginate-polyvinyl alcohol-bovin serum albumin coated $\mathrm{Fe}_{3} \mathrm{O}_{4}$ nanoparticles as anticancer drug delivery vehicle: doxorubicin loading and in vitro release study and cytotoxicity to HepG2 and L02 cells. Mater Sci Eng. 2017;79:410-422.

145. Erdem M, Yalcin S, Gunduz U. Folic acid-conjugated polyethylene glycol-coated magnetic nanoparticles for doxorubicin delivery in cancer chemotherapy: preparation, characterization and cytotoxicity on HeLa cell line. Hum Exp Toxicol. 2017;36(8):833-845.

146. $\mathrm{Xu} \mathrm{D}, \mathrm{Xu} \mathrm{T}$, Guo X, et al. Effect of the synthesis method on the performance of $\mathrm{Fe}_{3} \mathrm{O}_{4}$ inositol hexaphosphate as a drug delivery vehicle for combination therapeutics with doxorubicin. New J Chem. 2017;41(13):5305-5312.

147. Long R, Liu Y, Wu S, Wang S, Wang P. Co-delivery of doxorubicin and small interfering RNA with genipin-cross-linked iron (III) oxide-polyetherimide nanoparticles for combined cancer therapy. Nanomaterials Nanotechnology. 2017;7:184798041770409. 
148. Abasian M, Hooshangi V, Moghadam PN. Synthesis of polyvinyl alcohol hydrogel grafted by modified $\mathrm{Fe}_{3} \mathrm{O}_{4}$ nanoparticles: characterization and doxorubicin delivery studies. Iranian Polymer J. 2017;26(5):313-322.

149. Benyettou F, Fahs H, Elkharrag R, et al. Selective growth inhibition of cancer cells with doxorubicin-loaded CB[7]-modified iron-oxide nanoparticles. RSC Advances. 2017;7(38):23827-23834.

150. Arachchige MP, Laha SS, Naik AR, Lewis KT, Naik R, Jena BP. Functionalized nanoparticles enable tracking the rapid entry and release of doxorubicin in human pancreatic cancer cells. Micron. 2017;92:25-31.

151. Varshosaz J, Hassanzadeh F, Aliabadi HS, Khoraskani FR, Mirian M, Behdadfar B. Targeted delivery of doxorubicin to breast cancer cells by magnetic LHRH chitosan bioconjugated nanoparticles. Int J Biol Macromol. 2016;93(Pt A):1192-1205.

152. Peng N, Wu B, Wang L, et al. High drug loading and $\mathrm{pH}-$-responsive targeted nanocarriers from alginate-modified SPIONs for anti-tumor chemotherapy. Biomater Sci. 2016;4(12):1802-1813.

153. Sharifabad ME, Mercer T, Sen T. Drug-loaded liposome-capped mesoporous core-shell magnetic nanoparticles for cellular toxicity study. Nanomedicine. 2016;11:2757-2767.

154. Wu L, Zhang Z, Li H, Wei W, Liu S. Fe $\mathrm{O}_{4}$-capped mesoporous silica foam for $\mathrm{pH}$-responsive drug delivery. J Nanosci Nanotechnol. 2016;16:6781-6787.

155. Komarala EP, Nigam S, Aslam M, Bahadur D. In-vitro evaluation of layered double hydroxide- $\mathrm{Fe}_{3} \mathrm{O}_{4}$ magnetic nanohybrids for thermochemotherapy. New J Chem. 2016;40(1):423-433.

156. Chen L, Wu L, Liu F, Qi X, Ge Y, Shen S. Azo-functionalized $\mathrm{Fe}_{3} \mathrm{O}_{4}$ nanoparticles: a near-infrared light triggered drug delivery system for combined therapy of cancer with low toxicity. J Mater Chem. 2016;4(21):3660-3669.

157. Wang X, Chang Y, Zhang D, Tian B, Yang Y, Wei F. Transferrinconjugated drug/dye-co-encapsulated magnetic nanocarriers for active-targeting fluorescent/magnetic resonance imaging and antitumor effects in human brain tumor cells. RSC Advances. 2016;6(107): 105661-105675.

158. Luo X, Wang Y, Lin H, Qu F. DOX-Fe $\mathrm{O}_{4} @ \mathrm{mSiO}_{2}-\mathrm{PO}-\mathrm{FA}$ nanocomposite for synergistic chemo- and photothermal therapy. RSC Advances. 2016;6:112232-112240.

159. Gupta J, Mohapatra J, Bhargava P, Bahadur D. A pH-responsive folate conjugated magnetic nanoparticle for targeted chemo-thermal therapy and MRI diagnosis. Dalton Trans. 2016;45(6):2454-2461.

160. Wang X, Jing X, Zhang X, et al. A versatile platform of magnetic microspheres loaded with dual-anticancer drugs for drug release. Mater Chem Phys. 2016;177:213-219.
161. Li X, Yang Y, Jia Y, et al. Enhanced tumor targeting effects of a novel paclitaxel-loaded polymer: PEG-PCCL-modified magnetic iron oxide nanoparticles. Drug Deliv. 2017;24(1):1284-1294.

162. Tian J, Yan C, Liu K, et al. Paclitaxel-loaded magnetic nanoparticles: synthesis, characterization, and application in targeting. J Pharm Sci. 2017;106(8):2115-2122.

163. Vismara E, Bongio C, Coletti A, et al. Albumin and hyaluronic acid-coated superparamagnetic iron oxide nanoparticles loaded with paclitaxel for biomedical applications. Molecules. 2017; 22(7):1030

164. Koutsiouki K, Angelopoulou A, Ioannou E, et al. TAT peptideconjugated magnetic PLA-PEG nanocapsules for the targeted delivery of paclitaxel: in vitro and cell studies. AAPS Pharm Sci Tech. 2017;18(3):769-781

165. Zheng XC, Ren W, Zhang S, et al. The theranostic efficiency of tumor-specific, $\mathrm{pH}$-responsive, peptide-modified, liposome-containing paclitaxel and superparamagnetic iron oxide nanoparticles. Int $J$ Nanomedicine. 2018;13:1495-1504.

166. Lu B, Huang X, Mo J, Zhao W. Drug delivery using nanoparticles for cancer stem-like cell targeting. Front Pharmacol. 2016;7(065103):84.

167. Ray Chowdhuri A, Bhattacharya D, Sahu SK. Magnetic nanoscale metal organic frameworks for potential targeted anticancer drug delivery, imaging and as an MRI contrast agent. Dalton Trans. 2016; 45(7):2963-2973.

168. Chatzipavlidis A, Bilalis P, Efthimiadou EK, Boukos N, Kordas GC. Sacrificial template-directed fabrication of superparamagnetic polymer microcontainers for $\mathrm{pH}$-activated controlled release of daunorubicin. Langmuir. 2011;27(13):8478-8485.

169. Wang J, Chen B, Chen J, et al. Synthesis and antitumor efficacy of daunorubicin-loaded magnetic nanoparticles. Int $J$ Nanomedicine. 2011;6:203.

170. Wang J, Chen B, Cheng J, et al. Apoptotic mechanism of human leukemia K562/A02 cells induced by magnetic iron oxide nanoparticles coloaded with daunorubicin and 5-bromotetrandrin. Int J Nanomedicine. 2011;6:1027.

171. Hosseini L, Mahboobnia K, Irani M. Fabrication of PLA/MWCNT/ $\mathrm{Fe}_{3} \mathrm{O}_{4}$ composite nanofibers for leukemia cancer cells. Int J Polym Mater Polymer Biomater. 2016;65(4):176-182.

172. Maiti D, Saha A, Devi PS. Surface modified multifunctional ZnFe2O4 nanoparticles for hydrophobic and hydrophilic anti-cancer drug molecule loading. Phys Chem Chem Phys. 2016;18(3):1439-1450.

173. Chen Z. Small-molecule delivery by nanoparticles for anticancer therapy. Trends Mol Med. 2010;16:594-602.
International Journal of Nanomedicine

\section{Publish your work in this journal}

The International Journal of Nanomedicine is an international, peerreviewed journal focusing on the application of nanotechnology in diagnostics, therapeutics, and drug delivery systems throughout the biomedical field. This journal is indexed on PubMed Central, MedLine, CAS, SciSearch $®$, Current Contents $\AA /$ Clinical Medicine,

\section{Dovepress}

Journal Citation Reports/Science Edition, EMBase, Scopus and the Elsevier Bibliographic databases. The manuscript management system is completely online and includes a very quick and fair peer-review system, which is all easy to use. Visit http://www.dovepress.com/ testimonials.php to read real quotes from published authors. 